\title{
"The Part of Me That You Bring Out": Ideal Similarity and the Michelangelo Phenomenon
}

\author{
Caryl E. Rusbult \\ Vrije Universiteit Amsterdam \\ Kaska E. Kubacka \\ Vrije Universiteit Amsterdam
}

\author{
Madoka Kumashiro \\ Goldsmiths, University of London \\ Eli J. Finkel \\ Northwestern University
}

\begin{abstract}
This work examines the Michelangelo phenomenon, an interpersonal model of the means by which people move closer to (vs. further from) their ideal selves. The authors propose that partner similaritysimilarity to the ideal self, in particular-plays an important role in this process. Across 4 studies employing diverse designs and measurement techniques, they observed consistent evidence that when partners possess key elements of one another's ideal selves, each person affirms the other by eliciting important aspects of the other's ideals, each person moves closer to his or her ideal self, and couple well-being is enhanced. Partner similarity to the actual self also accounts for unique variance in key elements of this model. The associations of ideal similarity and actual similarity with couple well-being are fully attributable to the Michelangelo process, to partner affirmation and target movement toward the ideal self. The authors also performed auxiliary analyses to rule out several alternative interpretations of these findings.
\end{abstract}

Keywords: Michelangelo phenomenon, partner affirmation, ideal self, ideal similarity, actual similarity

I love you not only for what you are, but for what I am when I am with you. I love you not only for what you have made of yourself, but for what you are making of me. I love you for the part of me that you bring out.

— Elizabeth Barrett Browning ${ }^{1}$

Most research regarding goal pursuits examines the self in isolation, testing intrapersonal explanations of how people acquire skills, traits, and accomplishments (cf. Carver \& Scheier, 1998; Chartrand \& Bargh, 2002). We suggest that this approach is somewhat person-centric. Granted, people often accomplish things through their own, independent actions. But just as often, close partners play a role in one another's goal strivings. Indeed, pioneers in our field reasoned that the self is socially constructed, arguing that personal dispositions and skills are shaped by interpersonal forces and suggesting that goals are achieved in part via interpersonal means (cf. Cooley, 1902;

Caryl E. Rusbult and Kaska E. Kubacka, Department of Social Psychology, Vrije Universiteit Amsterdam, Amsterdam, the Netherlands; Madoka Kumashiro, Department of Psychology, Goldsmiths, University of London, London, England; Eli J. Finkel, Department of Psychology, Northwestern University.

This research was supported by (a) National Science Foundation Grant BCS-0132398 and the Vrije Universiteit Amsterdam Bruidschat Award to Caryl E. Rusbult and by (b) Netherlands Organization for Scientific Research Grant NWO-040-11-020 to Eli J. Finkel.

Correspondence concerning this article should be addressed to Caryl E. Rusbult, Department of Social Psychology, Vrije Universiteit Amsterdam, Van der Boechorststraat 1, 1081 BT Amsterdam, the Netherlands. E-mail: ce.rusbult@psy.vu.nl
James, 1890). This proposition was beautifully expressed by Elizabeth Barrett Browning, who proclaimed that she loved her partner not only because of the fine qualities he possessed and the admirable goals he pursued but also because of how he shaped her own qualities and goal pursuits, because of what he "brought out in her" and helped "make of her."

Consistent with this proposition, research regarding the Michelangelo phenomenon has demonstrated that in harmonious relationships, close partners promote one another's ideal selves, and each person is likely to move closer to achieving his or her ideals (Drigotas, Rusbult, Wieselquist, \& Whitton, 1999). This being the case, it seems likely that relationships science may illuminate our knowledge of why some partners contribute to one another's goal strivings, whereas others do not. The present research examines the role that partner similarity-similarity to the ideal self, in particular-may play in this process. In the following article, we introduce the Michelangelo phenomenon, explain how and why ideal similarity might contribute to this process, and report findings from four studies designed to test key predictions of our model.

\footnotetext{
${ }^{1}$ The provenance of this quotation is ambiguous, although it frequently is attributed to Elizabeth Barrett Browning. These words surely are reflective of what she might have said—or thought—about her husband, Robert Browning. At the same time, it is unclear whether this prose properly should be attributed to Elizabeth Barrett Browning, Ray Croft, Mary Carolyn Davies, or "Anonymous." We are grateful to Linda Shires of Syracuse University for providing information and insight regarding this matter.
} 


\section{The Michelangelo Phenomenon}

Michelangelo Buonarroti described sculpting as a process whereby the artist releases an ideal figure from the block of stone in which it slumbers. The sculptor's task is simply to chip away at the stone so as to reveal the ideal form (Gombrich, 1995). Humans, too, possess ideal forms. The ideal self represents the individual's hopes, dreams, and aspirations, or the constellation of skills, traits, and accomplishments that an individual ideally wishes to acquire (Higgins, 1987; Markus \& Nurius, 1986). Whether the ideal self is internally represented in terms of clearly defined goals or in terms of vague and tacit yearnings, individuals' dreams and aspirations serve a powerful regulatory function, in that people desire positive changes in their selves; that is, people seek to grow, reducing the discrepancy between the actual self and the ideal self (cf. Higgins, 1997).

Although people sometimes achieve ideal-relevant goals through their own actions, the acquisition of new skills, traits, and accomplishments is also shaped by interpersonal experience. Such influence is likely to be particularly powerful in close relationships, in that people adapt to one another during the course of everyday interaction, changing their behavior so as to coordinate with one another and enjoy good outcomes (Kelley \& Thibaut, 1978). Behavioral adaptations are especially common in close relationships, in that interdependence entails strong and frequent influence across diverse behavioral domains (Kelley et al., 1983). Over the course of extended interaction, adaptations that begin as interaction-specific adjustments often become stable components of the self, such that over time, close partners sculpt one another's selves (Kelley, 1983; Rusbult \& Van Lange, 2003).

Partner affirmation describes the nature of a partner's influence, or the degree to which a partner elicits key elements of the target's ideal self. Affirmation may come about through either conscious or unconscious cognition regarding the target's ideals and may entail controlled or automatic processes. For example, Robert may affirm Elizabeth's ideal self by exhibiting automatic positive responses to her ideal-congruent behaviors, by unconsciously prompting ideal-congruent acts, by creating situations in which ideal-congruent actions pay off, by behaving as though she possesses ideal-congruent qualities, or simply by enacting ideal-congruent behaviors himself (e.g., via selective instigation, situation selection, modeling). Of course, partners may also disaffirm one another. Robert may be indifferent to Elizabeth's hopes and aspirations, he may disapprove of her ideals, he may consciously or unconsciously undermine her ideal pursuits, he may affirm qualities that are immaterial to her ideal self, or he may deliberately or automatically affirm qualities that are part of his own ideal self rather than hers. ${ }^{2}$

Thus, pursuit of the ideal self may not be a solitary activity. As noted in Figure 1, we propose that partner affirmation yields target movement toward the ideal self: The target enjoys reductions in actual-self/ideal-self disparities, increasingly coming to resemble his or her ideal self. Moreover, we suggest that couple well-being is based in part on what partners bring out in one another and make of one another: that affirmation and movement toward the ideal self yield enhanced couple well-being, or greater vitality, happiness, trust, and commitment. Why so? Given that growth striving is a primary human motive (cf. Aron
\& Aron, 2000; Deci \& Ryan, 2000), when two people join forces to promote one another's growth, their relationship is strengthened. Prior research has revealed good support for these claims: When Elizabeth and Robert affirm important components of one another's ideal selves, each person enjoys greater movement toward his or her ideal self, and their relationship is enhanced (e.g., Drigotas, 2002; Drigotas et al., 1999; Kumashiro, Rusbult, Finkenauer, \& Stocker, 2007).

\section{Partner Similarity to the Ideal Self and the Michelangelo Phenomenon}

How might partner similarity contribute to this process? In relationships science, it is a truism that similarity yields good outcomes. Innumerable empirical studies support the claim that attraction and couple well-being are promoted by actual similarity, or the extent to which a partner possesses (or is perceived to possess) attitudes and traits that are part of one's actual self (e.g., Byrne, 1971; Caspi, Herbener, \& Ozer, 1992; Luo \& Klohnen, 2005; Rosenbaum, 1986). The benefits of actual similarity frequently are explained in terms of cognitive balance, implied liking, or social comparison (cf. Byrne, Ervin, \& Lamberth, 1970; Condon \& Crano, 1988; Newcomb, 1961). Some empirical studies also support the claim that attraction is promoted by ideal similarity, defined as the extent to which a partner possesses attributes and traits that are part of (a) one's ideal self standards, or (b) one's ideal partner standards (e.g., Fletcher, Simpson, \& Thomas, 2000; Klohnen \& Luo, 2003; LaPrelle, Hoyle, Insko, \& Bernthal, 1990; Murray, Holmes, Bellavia, Griffin, \& Dolderman, 2002; Wetzel \& Insko, 1982). Such effects frequently are explained in terms of aesthetic judgments: Partners who resemble our ideals compare favorably to our ideal standards of quality and worthiness (cf. LaPrelle et al., 1990; Zentner, 2005). However, in light of the robustness of similarity effects over the course of long-term interdependence (e.g., Caspi et al., 1992; Murray et al., 2002), we believe that similarity may serve functions that extend beyond cognitive balance, implied liking, or aesthetic judgments. We propose that partner similarity-similarity to the ideal self, in particular-may also serve a more thoroughly interpersonal function, via its impact on the Michelangelo process.

Why should partner similarity to one's ideals promote the Michelangelo process? In the present work, ideal similarity is

\footnotetext{
${ }^{2}$ In early work regarding the Michelangelo phenomenon, we examined two components of partner affirmation, distinguishing between (a) partner perceptual affirmation - perceiving the target in a manner that is congruent with the target's ideal self (e.g., believing in the target's capacity to achieve his or her ideals) - and (b) partner behavioral affirmation-behaving toward the target in a manner that is congruent with the target's ideal self (e.g., eliciting ideal-congruent behaviors from the target; Drigotas et al., 1999). In early research, as well as in more recent work (including the present research), we have found that partner behavioral affirmation accounts for unique variance beyond perceptual affirmation and mediates the associations of perceptual affirmation with later model variables. For the sake of simplicity, in the present research, we examine partner behavioral affirmation as the proximal consequence of ideal similarity and as the proximal cause of target movement toward ideal.
} 


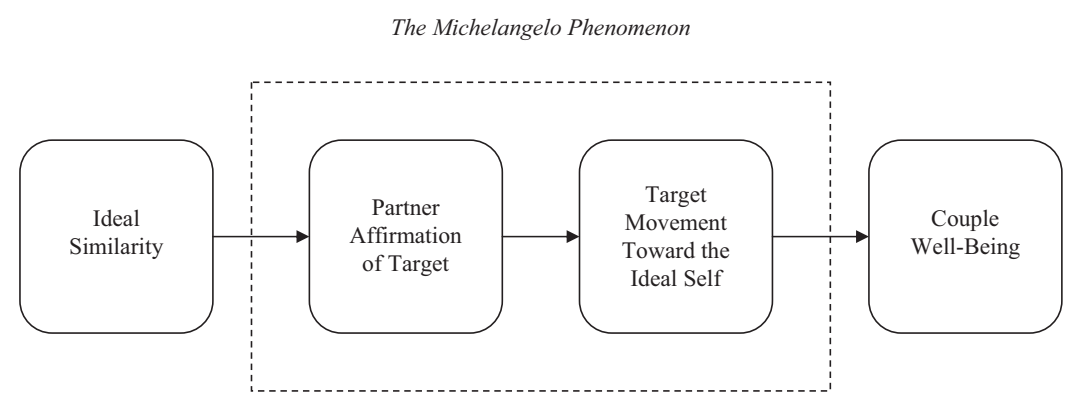

Figure 1. Predicted associations among ideal similarity, partner affirmation of target, target movement toward the ideal self, and couple well-being.

defined as the extent to which a partner possesses attitudes and traits that are part of one's ideal self. As noted in Figure 1, we propose that ideal similarity promotes partner affirmation-that partners who possess key elements of one another's ideals are likely to be more insightful, skilled, and motivated sculptors. For example, when Robert possesses key elements of Elizabeth's ideal self, he may consciously or unconsciously display traits or values that promote her ideals, he may suggest effective strategies by which she might pursue her goals, or he may exhibit approval of her strivings (Drigotas et al., 1999; Kumashiro et al., 2007). We also suggest that ideal similarity is associated with target movement toward the ideal self and couple well-being; these associations should be at least partially attributable to the impact of ideal similarity on partner affirmation. Mediation may be partial, rather than complete, because beyond variance attributable to partner affirmation, ideal similarity may also (a) directly influence target movement toward ideal (Elizabeth may incorporate Robert's attributes into her behavioral repertoire via target-centered mechanisms such as assimilation, modeling, or self-other merger; e.g., Aron \& Aron, 2000; Bandura, 1986; Lockwood \& Kunda, 1997; Stapel \& van der Zee, 2006) and/or (b) directly influence couple well-being (Elizabeth and Robert may enjoy greater happiness or vitality because of enhanced value correspondence or reduced conflict).

Our predictions regarding the benefits of ideal similarity are challenging in that, arguably, it might not be an unalloyed joy to live with a partner who possesses key elements of one's ideal self. Numerous studies document the fact that high-performing partners (e.g., partners who resemble our ideal selves) frequently prompt aversive upward comparison and are psychologically threatening (e.g., Herbst, Gaertner, \& Insko, 2003; Tesser, 1988). We propose that, in comparison with highperforming strangers, high-performing close partners are substantially less likely to evoke threat in that close partners enjoy relatively greater assimilation of one another's successes, frequently benefit from one another's knowledge and resources, and serve as targets of capitalization, rather than competition (e.g., Aron \& Aron, 2000; Beach et al., 1998; Gable, Reis, Impett, \& Asher, 2004). As such, we expect that, in close relationships, the potential liabilities of ideal similarity will be outweighed by its benefits for growth and well-being.

But what about actual similarity? Although the present work is concerned primarily with the interpersonal functions of ideal similarity, we also examine actual similarity effects. Our main reason for examining the effects of actual similarity is to demonstrate that partner similarity to the ideal self accounts for unique variance beyond any benefits accruing from actual similarity. At the same time, we speculated that partner similarity to the actual self might account for unique variance beyond ideal similarity. For example, actual similarity may stand as a "reality check," serving as a reminder of one's realistic potential for growth: When Robert possesses key elements of Elizabeth's actual self, (a) he may exhibit greater partner affirmation-he may be more likely to recognize realistic impediments to achieving her ideals or identify practical strategies for pursuing her ideals-and/or (b) Elizabeth may enjoy greater movement toward her ideal selfRobert may serve as a model for how she may realistically achieve her ideals. Actual similarity might also (c) influence couple well-being, for example, by facilitating harmonious interaction. In short, our primary prediction is that ideal similarity will account for unique variance in model variables beyond actual similarity; in a more speculative vein, we also explore the possible direct and indirect associations of actual similarity with model criteria.

\section{Research Overview}

The present work was inspired by several broad goals: To begin with, we sought to extend the literature regarding self processes by demonstrating the role that close partners play in shaping each person's pursuit of the ideal self. It is important to note that this is the first work to identify a couple-level predictor of the Michelangelo phenomenon: We suggest that when each person possesses key components of the other's ideal self, partners are likely to affirm one another's ideals, and each person is likely to move closer to his or her ideals. An additional, complementary goal was to extend relationships science by examining an interdependence-based explanation of similarity effects. In particular, we propose that partner similarity serves an important interpersonal function, that ideal similarity enhances couple functioning, not merely because it is aesthetically pleasing or sustains cognitive balance but also because it promotes each person's growth via the Michelangelo process.

As displayed in Figure 1, we predict that (a) ideal similarity will be positively associated with partner affirmation, target movement toward the ideal self, and couple well-being. In addition, we explore the basis for the benefits of ideal similar- 
ity, predicting that (b) the benefits of ideal similarity for target movement toward the ideal self will be partially or wholly mediated by partner affirmation, and (c) the benefits of ideal similarity for couple well-being will be partially or wholly mediated by partner affirmation and target movement toward ideal. We also examine the Michelangelo phenomenon per se, predicting that (d) partner affirmation will promote target movement toward the ideal self, and (e) target movement toward the ideal self will promote couple well-being. We also predict that (f) ideal similarity will account for unique variance beyond actual similarity, and explore several subsidiary goals, including ( $\mathrm{g}$ ) whether actual similarity accounts for unique variance beyond ideal similarity and (h) by what mechanisms ideal similarity promotes partner affirmation (e.g., dedication to target goals, skill at affirmation).

Our empirical tests rest on a converging operations approach. Across four studies, we employ both nonexperimental methods (Studies 1 and 2) and experimental methods (Study 3) to test our hypotheses and use longitudinal data to examine the degree to which earlier model variables predict change over time in model criteria (Study 4). We also make use of both direct and indirect indices of partner similarity and adopt diverse techniques to measure model criteria, using data from self-report questionnaires and friend-report questionnaires, data from an 8-day daily diary procedure, and both participant ratings and coder ratings of partners' behaviors during videotaped conversations. As such, the strengths of one study compensate for the limitations of other studies. Moreover, following Study 4 we include an Auxiliary Analyses section, presenting findings from (a) challenging across-partner analyses for Studies 1 and 2 (i.e., target-reported predictors, partner-reported criteria), (b) numerous analyses that help rule out alternative explanations of our results (e.g., inclusion of other in the self, global social support), and (c) the results of a meta-analytic summary of all direct and indirect associations among model variables. Collectively, these data provide a very good basis for inferences regarding the processes we seek to elucidate.

\section{Study 1}

In Study 1, we explored the validity of our model in a study of newly committed couples, employing three means of measuring model variables. First, we assessed model variables using participants' self-reports of their own and the partner's everyday behavior in their relationship. Second, we videotaped partners' ideal-relevant interactions, later asking participants to rate their own and the partner's behavior during the conversation (cf. Ickes, Bissonnette, Garcia, \& Stinson, 1990). And third, we developed a coding scheme for rating ideal-relevant interactions, asking trained coders to rate target and partner behaviors during the conversation (cf. Gottman, 1979). We hypothesized that ideal similarity would be positively associated with partner affirmation, target movement toward the ideal self, and couple well-being. In addition, we hypothesized that the association of ideal similarity with target movement toward the ideal self would be at least partially mediated by partner affirmation and that the association of ideal similarity with couple well-being would be at least partially mediated by partner affirmation and target movement toward ideal.

\section{Method}

Participants. The data for Study 1 are from 187 couples who took part in Time 1 activities of a five-wave longitudinal study of newly committed couples (183 heterosexual couples, 4 lesbian couples). ${ }^{3}$ Couples were paid $\$ 80$ for taking part in Time 1 activities. At Time 1, participants were 24.97 years old, on average $(S D=4.62)$. Partners had been involved with one another for about 38 months $(S D=24.55)$, most couples dated steadily or were engaged or married (25\% dating steadily, $29 \%$ engaged, $38 \%$ married, $8 \%$ other), and most lived together $(84 \%)$

Procedure. Participants were recruited via announcements posted in the Chapel Hill, North Carolina, community. The requirement for participation was that couples be "newly committed": At the beginning of the study, couples had begun living with one another, become engaged, or married one another within the previous year or planned to do so during the coming year. Couples took part in project activities once every 6 months. Prior to Time 1 laboratory sessions, participants were mailed questionnaires that they completed in advance and brought with them to the research session. During laboratory sessions, partners completed additional questionnaires and engaged in a videotaped conversation about each person's pursuit of his or her ideal self. At the end of the session, couples were partially debriefed, paid, and thanked for their assistance.

Self-report questionnaires. Participants completed questionnaires prior to or during Time 1 sessions. We measured ideal similarity using three items developed for the purpose of the present work (e.g., "My partner possesses the qualities that I ideally would like to possess"; "I wish I could be more like my partner"; $0=$ do not agree at all, $8=$ agree completely; $\alpha=$ .84). We measured partner affirmation of target using four items that paralleled those employed in previous work (Drigotas et al., 1999; e.g., "My partner treats me in a way that is close to the person I ideally would like to be"; "My partner elicits the best that I might possibly become"; $0=$ do not agree at all, $8=$ agree completely; $\alpha=.87$ ). To measure target movement toward ideal, we asked participants to think about their ideal selves - their "goals, dreams, and aspirations, or the person you ideally would like to be"-and to list the six most important components of their ideal self. Participants identified diverse components of their ideal selves, including professional, personal, and social goals (e.g., "finish my masters," "direct a documentary," "exercise more," "do some pro bono work," "be a more selfless person," "get out more," "become closer to God"). Later, they rated the extent to which they had moved closer to achieving each of their top six ideals $(-4=I$ have moved further from achieving this goal, $0=I$ have not changed,$+4=$ I have moved closer to achieving this goal; $\alpha=$ .61). We measured couple well-being using a 30-item version of the Dyadic Adjustment Scale that taps components of couple functioning, such as agreement regarding important values (re-

\footnotetext{
${ }^{3}$ Several of our studies employ data from this project: Study 1 uses concurrent data from Time 1 of this project, Study 2 uses concurrent data from Time 3 of this project, and Study $4 \mathrm{a}$ uses time-series data from Times 3 and 4 of this project.
} 
ligion, decision making), conflict management, and expressions of love and affection (Spanier, 1976; e.g., "Do you confide in your partner?"; $0=$ never, $5=$ all the time; $\alpha=.87){ }^{4}$

Ideal-relevant interactions. We also assessed behavior during ideal-relevant interactions. Couples engaged in two conversations, one about each person's ideal self. We selected topics from participants' descriptions of their top six ideals, identifying a component of each person's ideal self that was important to the participant, that had not yet been achieved but was likely to be achieved during the next 5 to 10 years, and that the participant was willing to discuss. Partners discussed diverse aspects of their ideal selves, including professional goals, interpersonal goals, and personal dispositions or skills. Following a 2-min warm-up interaction (discussing the events of the previous day), we explained that we had randomly determined which person's topic would be addressed first and read that person's ideal description aloud. Partners engaged in a 6-min discussion of the ideal (e.g., how might the ideal be achieved, are there obstacles to achieving it, what are the implications of this ideal for other parts of their lives?).

To obtain participant ratings of ideal-relevant interactions, following the two conversations, we seated partners in separate rooms, each facing a monitor on which the videotaped conversations were replayed. The experimenter stopped the videotape at the end of each 2-min segment, asking participants to rate their own and the partner's behavior during that segment. We developed a measure of partner affirmation of target by averaging participants' ratings of affirmation across the three 2-min segments (one item; "My partner said and did things that helped me move closer to my goal"; for all ratings, $0=$ do not agree at all, $8=$ agree completely; $\alpha$ across three segments $=.89$ ). After rating all three 2-min segments, participants also described the conversation as a whole, rating target movement toward ideal (one item; "I moved closer to attaining my goal") and composite indices of couple adjustment during interaction (four items; e.g., "During this conversation, I felt that I could really trust my partner"; "During this conversation, I felt very committed to our relationship"; $\alpha=.88$ ).

We also developed a coding scheme for use in obtaining coder ratings of ideal-relevant interactions, asking two trained coders to independently rate targets' and partners' behaviors during each 2-min segment. We developed a measure of partner affirmation of target by averaging coders' ratings of affirmation across the three 2-min segments (using a 28-item coding scheme that examined positive vs. negative instrumental vs. emotional partner behaviors; e.g., "encouraged target," "conveyed understanding of target"; for all ratings, $1=$ not at all evident, 5 = clearly evident; $\alpha$ across three segments $=.94)$. After rating all three 2-min segments, coders also described the conversation as a whole, rating target movement toward ideal (one item; "By the end of the conversation, target was motivated to attain goal") and satisfaction with interaction (two items; e.g., "Process seemed to be positive for partners"; $\alpha=.82)$.

\section{Results and Discussion}

Analysis strategy. The data from the two partners in a relationship are nonindependent, so we analyzed our data using hierarchical linear modeling, representing the data from partners as nested within couple (Raudenbush \& Bryk, 2002). This technique accounts for nonindependence by simultaneously examining vari- ance associated with each level of nesting, thereby providing unbiased hypothesis tests. Following recommended procedures for couples research, we represented intercept terms as random effects and represented slopes as fixed effects (Kenny, Kashy, \& Cook, 2006). We initially performed key analyses including gender as a lower level variable; fewer than $15 \%$ of the gender effects were significant, and this variable did not moderate our findings in reliable or meaningful ways, so we dropped gender from the analyses.

Predicting key model variables. We hypothesized that, to the extent that the partner possessed key elements of the target's ideal self, targets would receive greater partner affirmation, enjoy greater movement toward their ideal selves, and experience enhanced couple well-being (e.g., dyadic adjustment, satisfaction with interaction). To test these predictions, we regressed each criterion-as assessed using self-report questionnaire variables (see the upper portion of Table 1), participant ratings of interactions (see the middle portion of Table 1), and coder ratings of interactions (see the lower portion of Table 1) - onto participants' self-reports of ideal similarity. Consistent with predictions, ideal similarity exhibits significant positive associations with eight of nine criteria: with partner affirmation of target (three of three effects), target movement toward the ideal self (two of three effects), and couple well-being (three of three effects). These findings are particularly striking in that the predicted associations are evident not only for criteria as measured in self-report ques-

\footnotetext{
${ }^{4}$ Our Study 1 self-report variables employ a target perspective, assessing each participant's experiences as the target of affirmation: As noted above, participants reported on perceived partner affirmation (how affirming is my partner of me?), target movement toward ideal (how well am I achieving my goals?), and couple well-being. In our primary analyses, we employed self-report measures using this target perspective in that (a) targets may more reliably recognize partner affirmation than partners, in that affirmation may sometimes entail unconscious or automatic processes (processes of which the partner is unaware), and (b) targets may more reliably recognize the extent to which they move closer to achieving their ideals. However, we also obtained parallel self-report variables from a partner perspective, assessing participants' experiences as partner, rather than as target: From a partner perspective, participants also reported on partner affirmation (how affirming am I of my partner?), perceived target movement toward ideal (how well is my partner achieving his or her goals, for each of the top six goals identified by the target?), and couple wellbeing. In the Auxiliary Analyses section following Study 4, we report findings from across-partner analyses that employ these partnerperspective measures. For now, it is useful to note that, for each construct for which we obtained reports from both target and partner perspectives, we assessed the validity of our data by examining the association between measures of parallel constructs. In their self-report questionnaire measures, partners exhibited moderate agreement in their descriptions of partner affirmation ( $\beta=.35, p<.01$; e.g., his report of her affirmation of him with her report of her affirmation of him), target movement toward the ideal self ( $\beta=.46, p<.01$; e.g., his report of his movement with her report of his movement), and dyadic adjustment $(\beta=.35, p<.01)$. Moreover, participants' self-report measures were associated with ratings of target and partner behaviors during videotaped ideal-relevant conversations (described below). Participants' self-report measures of partner affirmation, target movement, and couple well-being were associated with participant ratings of ideal-relevant interactions $(\beta \mathrm{s}=.33, .23$, and .32 , respectively; all $p$ s $<.01)$ and with parallel coder ratings of ideal-relevant interactions $(\beta \mathrm{s}=.11, .11$, and .10 , respectively; all $p \mathrm{~s}<.01)$.
} 
Table 1

Associations of Ideal Similarity With Partner Affirmation, Target Movement Toward the Ideal Self, and Couple WellBeing, Study 1

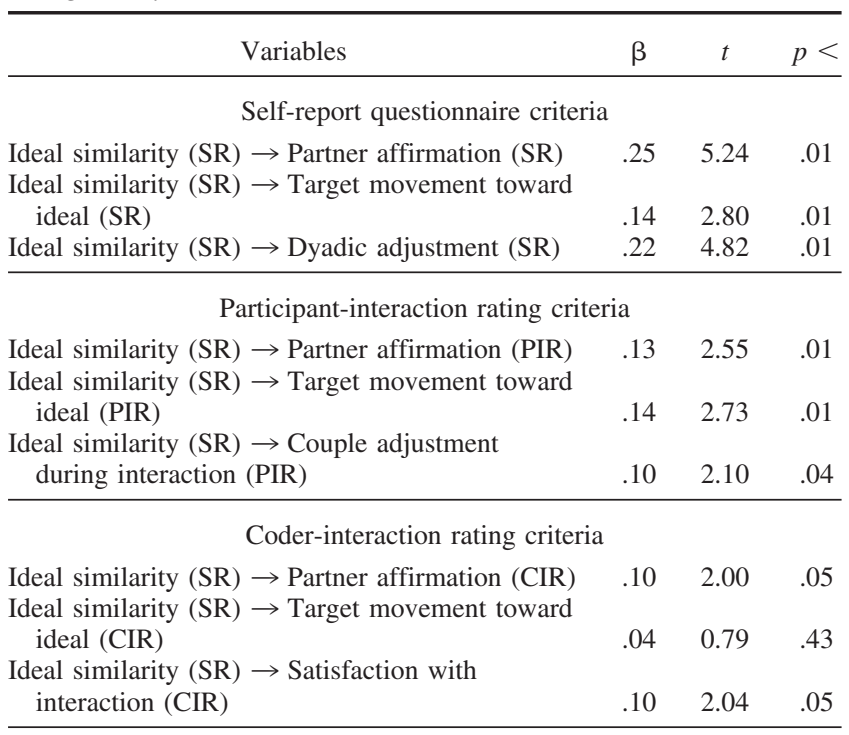

Note. $\quad \mathrm{SR}=$ self-report questionnaire variables; $\mathrm{PIR}=$ participant ratings of ideal-relevant interactions; CIR $=$ coder ratings of ideal-relevant interactions. Statistics are from hierarchical linear modeling analyses based on data from 160 to 182 couples (degrees of freedom for analyses ranged from 162 to 181 ); $N$ varies across analyses because of missing data for some variables.

tionnaires but also for criteria as measured in the context of a 6-min interaction regarding each person's ideal goal pursuits, as rated not only by participants but also by trained coders.

In addition to examining the associations of ideal similarity with each criterion, we examined the associations among partner affirmation, target movement toward the ideal self, and couple wellbeing. These analyses revealed patterns of association that are consistent with our broader model (see Figure 1): Partner affirmation is associated with target movement toward ideal (for selfreport variables, participant interaction ratings, and coder interaction ratings, $\beta \mathrm{s}=.26, .57$, and .60 , respectively; all $p s<.01$ ), and target movement toward ideal is associated with couple well-being (for self-report variables, participant-ratings, and coder-ratings, $\beta \mathrm{s}=.24, .26$, and .57 , respectively; all $p \mathrm{~s}<.01)$. We return to these findings in the Auxiliary Analyses section that follows Study 4 , in a meta-analytic review of results regarding direct and indirect effects in our model.

Mediation analyses. We also performed mediation analyses to assess the plausibility of our claims about why ideal similarity is beneficial (Baron \& Kenny, 1986; Kenny, Kashy, \& Bolger, 1998). Consistent with the model displayed in Figure 1, Sobel's tests revealed that (a) the association of ideal similarity with target movement toward ideal was wholly mediated by partner affirmation (for self-report criteria and participant-interaction-rating criteria, $z \mathrm{~s}=3.54$ and 2.51, respectively; both $p \mathrm{~s}<.01$ ), (b) the association of ideal similarity with couple well-being was partially to wholly mediated by partner affirmation (for self-report criteria, participant interaction rating criteria, and coder rating criteria, $z \mathrm{~s}=$
4.62, 2.53, and 1.99, respectively; all $p \mathrm{~s}<.05$ ), and (c) the association of ideal similarity with couple well-being was partially to wholly mediated by target movement (for self-report criteria and participant rating criteria, $z \mathrm{~S}=2.42$ and 2.62 , respectively; both $p s<.02)$. We could not assess mediation for two models involving coder ratings because ideal similarity was not significantly associated with coder ratings of target movement toward ideal.

Discussion. Study 1 revealed good support for the claim that, to the extent that partners possess key elements of one another's ideal selves, partners exhibit greater affirmation, targets enjoy greater movement toward their ideals, and couples exhibit greater well-being and vitality. Mediation analyses also supported our claims regarding the basis for the benefits of ideal similarity: Ideal similarity is positively associated with personal growth and couple well-being in part because it promotes the Michelangelo process. Mediation was complete for predictions of target movement toward the ideal self, and mediation was partial to complete for predictions of couple well-being. Our confidence that these findings are not attributable to response bias is enhanced by the fact that we observed support for our hypotheses not only in analyses employing self-report questionnaire variables but also in analyses employing both participant ratings and coder ratings of target and partner behaviors during ideal-relevant conversations.

\section{Study 2}

Study 1 revealed good support for the claim that ideal similarity is beneficial and also revealed findings that were consistent with predictions regarding the mediation of ideal similarity effects. Ideal similarity indeed appears to serve a crucial interpersonal function, shaping the manner in which close partners influence one another's pursuit of the ideal self. However, Study 1 findings rest on a direct, self-report measure of ideal similarity. In Study 2, we developed an alternative, indirect means of assessing this construct. Our technique involved using independent judgment tasks to assess (a) the degree to which each of numerous attributes are core elements of the target's ideal self (as well as his or her actual self) and (b) the degree to which the partner actually possesses each attribute. As in Study 1, we employed diverse means of measuring Michelangelo model variables. In addition to obtaining self-report measures of model variables, we also asked participants to identify friends who would provide parallel information about themselves and their relationships (cf. Drigotas et al., 1999). We also measured model variables in the context of an 8-day daily diary procedure, assessing each construct in situ, in the context of participants' everyday lives (cf. Reis \& Wheeler, 1991). We hypothesized that ideal similarity would be positively associated with key model variables, that ideal similarity would account for unique variance beyond actual similarity, and that the previously described patterns of mediation would be evident. Moreover, we examined six mechanisms by which ideal similarity might promote partner affirmation (e.g., when partners possess key elements of our ideals, are they more likely to exhibit genuine dedication to our goal pursuits or possess insight into how we might achieve our ideals?).

\section{Method}

Participants. The data for Study 2 are from two sources: (a) 274 participants who took part in Time 3 activities of the five- 
wave longitudinal study described in Study 1 (133 heterosexual couples, 4 lesbian couples) and (b) 191 friends (129 women, 62 men) who were recruited by participants to take part in Time 3 activities. Each couple was paid $\$ 120$ for taking part in Time 3 activities, and each friend was paid $\$ 30$ for taking part in his or her portion of the Time 3 activities. At Time 3, participants were 26.45 years old, on average $(S D=4.56)$. Partners had been involved with one another for about 52 months $(S D=24.23)$, most couples were married (14\% dating steadily, $18 \%$ engaged, $62 \%$ married, $6 \%$ other), and most lived together $(95 \%)$. Friends were 27.29 years old, on average $(S D=5.85)$. Participants reported that they had known their friends for 8.17 years, on average $(S D=7.23$ ). Most participants described their friends as good friends or best friends (4\% casual friends, 55\% good friends, 31\% best friends, $10 \%$ other), and most indicated that the friend was also a casual or good friend of the partner ( $8 \%$ acquaintances, 35\% casual friends, $49 \%$ good friends, $4 \%$ best friends, $4 \%$ other). In short, friends were in a good position to describe the participant, the participant's partner, and the relationship between the two.

Procedure. Prior to Time 3 laboratory sessions, we mailed participants questionnaires that they completed in advance and brought with them to the research session. During laboratory sessions, they completed additional questionnaires and also (a) took part in judgment tasks that allowed us to develop indirect indices of actual similarity and ideal similarity, (b) provided information relevant to conducting the friend-report portion of the study, and (c) received instructions and materials relevant to the daily diary procedure that they were to complete on the 8 days following the research session (described below). At the end of the session, couples were partially debriefed, were paid for all Time 3 activities except the (yet to be completed) daily diary component, and were thanked for their assistance.

Judgment tasks: Assessing ideal similarity and actual similarity. During Time 3 sessions, participants completed a "Story of My Partner" task, in which they rated the extent to which the partner possessed each of 26 attributes that they had not previously encountered in the study (e.g., "artistic [creative, imaginative, enjoys beauty, the arts]," "politically active [knowledgeable, involved in political activities]," religious [spiritual, holds to faith and beliefs]"; 0 = partner does not possess at all, 8 = partner possesses completely). Later in the session, independent of their judgments about the partner, they completed a "Describing My Actual Self and My Ideal Self" task, in which they reviewed a list of the same 26 attributes and made two sorts of judgments about themselves, checking the five attributes that best described "what you are actually like" and, separately, checking the five attributes that best described "what you would ideally like to be" (participants also rated their actual and ideal selves with respect to each attribute; e.g., $0=I$ do not possess at all, $8=$ I possess completely). There was not undue overlap between the items that participants checked as their top-five ideal self attributes and the items they checked as their top-five actual self attributes: Over 50\% checked two or fewer overlapping attributes.

We employed these judgment-task data to develop indices of ideal similarity and actual similarity. The target-relevant portions of our indices (top-five attributes) were always based on the attributes that participants themselves checked as most characteristic of their ideal selves and actual selves. But for the partnerrelevant components of each index (ratings of actual partner at- tributes), should we regard the participant's ratings or the partner's ratings as more valid? There are legitimate arguments to support either choice. On the one hand, partners' ratings of themselves arguably are realistic indices of the partner's actual self. On the other hand, the participant might be a better judge of partner attributes insofar as the partner's self is relevant to the participant's ideals and personal growth. Therefore, for the partner-relevant components of our indices, we calculated indices using both target and partner ratings of partner attributes.

To develop indices of ideal similarity, we calculated (a) mean target ratings of the partner's actual attributes for the five attributes the target selected as key elements of his or her ideal self (target ratings of partner; i.e., does my partner possess my core ideal self attributes, as I rate the partner's actual self?) and (b) mean partner ratings of the partner's actual attributes for the five attributes the target selected as key elements of his or her ideal self (partner ratings of partner; i.e., does my partner possess my core ideal self attributes, as my partner rates his or her actual self?). We calculated indices of actual similarity using parallel procedures (e.g., does my partner possess my core actual self attributes, as I rate the partner's actual self?). In evaluating the reliability of these indices, it is important to note that there is no a priori reason to anticipate that a partner would score uniformly high (or uniformly low) for all five of the attributes that best define the participant's ideal self (or the participant's actual self). Thus, it is not surprising that indices of ideal similarity (using target and partner ratings of partner attributes, respective $\alpha \mathrm{s}=.56$ and .53 ) and actual similarity (respective $\alpha \mathrm{s}=.53$ and .52 ) exhibited only moderate reliability (e.g., partners possessed some top-five attributes but not others). ${ }^{5}$

Self-report questionnaires. Participants completed questionnaires prior to or during Time 3 sessions. We measured partner

\footnotetext{
${ }^{5}$ In addition to checking their top five actual self and ideal self attributes, participants also provided ratings of their actual and ideal selves (e.g., $0=I$ do not possess at all, $8=$ I possess completely). Using these data, we also developed correlation-based indices of ideal similarity and actual similarity. For example, to measure ideal similarity, we calculated the within-couple correlation between targets' ratings of their ideal selves and partners' ratings of their actual selves. Here, too, we developed indices of ideal and actual similarity using both target and partner ratings of partner attributes. Preliminary analyses performed on these measures revealed that the correlation-based indices were associated with the top five indices for both ideal similarity (average $\beta=.37$; range $=.12-.55$ ) and actual similarity (average $\beta=.44$; range $=.21-.58$ ). We also examined the simple association of each index with our nine criteria (described below)-measures of partner affirmation, target movement toward ideal, and couple well-being, as assessed using self-report criteria, friend-report criteria, and daily diary criteriaand found that (a) for top five indices, associations with ideal and actual similarity were significant or marginal in $94 \%$ of the analyses, whereas (b) for correlationbased indices, associations with ideal and actual similarity were significant or marginal in $61 \%$ of the analyses. We believe that the top five indices are more reliable in that they use data for attributes about which the participant holds unambiguous opinions (i.e., those that best describe the ideal self or actual self), whereas the correlation-based measures use data for some unambiguous attributes (those with extremely high or low ratings) but also for ambiguous attributes (those with mid-range ratings), such that a correlation based on the full range of ratings is less reliable. To maximize the odds of identifying unique variance attributable to ideal versus actual similarity, we employed the top five judgment-task indices of ideal similarity and actual similarity (assessed using both target and partner ratings of partner attributes).
} 
affirmation $(\alpha=.84)$ and dyadic adjustment $(\alpha=.90)$ using the items that were employed in Study 1 . We measured target movement toward ideal using a new procedure. We asked participants to "think about your ideal self, or the overall person you aspire to become" and, for each of five domains, indicate whether they had changed during their involvement with the partner $(-4=I$ have moved further from my ideal self, $0=I$ have not changed, $+4=$ I have moved closer to my ideal self). The domains were professional aspirations, personal traits, relationship goals, other domains, and overall ideal self; for each domain, we included a parenthetical description (e.g., "other domains [e.g., hobbies, health, spirituality]"; $\alpha=$.78). Participants also completed questionnaires about the mechanisms by which ideal similarity might promote partner affirmation and movement toward the ideal self, including partner is dedicated to target's ideals (six items; e.g., "My partner dedicates a lot of thought and effort to helping me achieve my goals"; for all items, $0=$ do not agree at all, $8=$ agree completely; $\alpha=.85$ ), partner believes in target's potential (three items; e.g., "My partner believes that I can become the sort of person I ideally strive to become"; $\alpha=.85)$, partner is skilled at affirmation (three items; e.g., "My partner is very effective at helping me move closer to my ideal self"; $\alpha=.69$ ), partner challenges target (three items; e.g., "My partner challenges me to become my ideal self"; $\alpha=.71)$, partner offers ideal-pursuit strategies (three items; e.g., "My partner is good at developing strategies I can use to achieve my goals"; $\alpha=.84$ ), and partner is responsive (three items; e.g., "My partner understands why I care about my goals"; $\alpha=.82$ ). ${ }^{6}$

Friend-report questionnaires. We asked each participant to locate a friend to complete a brief questionnaire, identifying friends with whom they were moderately close, who were at least moderately aware of their goals, and who had at least moderate knowledge of the participant's romantic relationship. The friend could be of either sex but could not be the same person as the partner selected. Prior to Time 3 sessions, participants identified suitable friends and inquired about their willingness to participate; during Time 3 sessions, they gave us their friends' contact information. We mailed each friend a packet of materials, including a cover letter, an informed consent form, and a questionnaire. Items in friends' questionnaires paralleled those in participants' questionnaires, except that they were worded so as to assess friends' perceptions of the participant and his or her relationship. We developed separate questionnaires for the friends of male and female participants so that friends could more readily comprehend items that referred to the participant (e.g., "my friend," "she") and the participant's partner (e.g., "her partner," "he"; we developed a separate questionnaire for lesbian relationships). We measured partner affirmation using four 9-point items (e.g., "Her partner behaves in ways that help her become who she most wants to be"; $0=$ do not agree at all, $8=$ agree completely; $\alpha=.90)$. To measure target movement toward ideal, we asked friends to "think about your friend's ideal self, or the overall person your friend aspires to become." Friends indicated whether the participant had changed during involvement with the partner with respect to each of the five domains described earlier for self-report questionnaires $(-4=$ she has moved further from her ideal self, $0=$ she has not changed, $+4=$ she has moved closer to her ideal self; $\alpha=.76$ ). We assessed couple well-being using an eight-item subset of the Dyadic Adjustment Scale (Spanier, 1976; e.g., "They frequently 'get on one another's nerves'"; $0=$ do not agree at all, $8=$ agree completely; $\alpha=.81$ ). When friends returned completed questionnaires, we sent them thank-you letters, along with payment for participation.

Daily diary procedure. We also measured model variables in situ, asking participants to complete a record regarding their daily activities at the end of each day over the 8-day period following the research session. Diary records included items to assess partner affirmation (one item; "My partner said and did things that helped me move closer to my goals"; for all items, $1=$ do not agree at all, $5=$ agree completely; $\alpha$ across 8 days $=.80$ ), target movement toward ideal (one item; "I feel close to attaining my goals"; $\alpha$ across 8 days $=.87$ ), and satisfaction with relationship (one item; "I felt good about our relationship today"; $\alpha$ across 8 days $=.84$ ). We developed a single measure of each model variable by averaging diary scores across the 8 days. Participants returned questionnaires following Days 4 and 8. At the end of the 8-day period, they completed exit questionnaires that inquired about the reliability and validity of their diary records (e.g., did they complete records each evening, were their records accurate?); participants described their records as moderately to highly timely, accurate, and representative. When couples had returned all of their completed materials, we mailed them thank-you letters, along with $\$ 60$ payment for the diary component.

\section{Results}

Analysis strategy. As in Study 1, given that the data from two partners in a relationship are nonindependent—as are data from the participant and his or her friend-we analyzed our data using hierarchical linear modeling, representing intercepts as random effects and representing slopes as fixed effects. And as in Study 1, we initially performed key analyses including gender as a lower level variable; fewer than $10 \%$ of the gender effects were significant, so we dropped this variable from the analyses.

Predicting key model variables. We hypothesized that ideal similarity — and perhaps actual similarity, as well—would be positively associated with partner affirmation, target movement toward ideal, and couple well-being. To begin with, we examined the

\footnotetext{
${ }^{6}$ As in Study 1, our Study 2 self-report variables employ a target perspective, assessing each participant's experiences as the target of affirmation. And as in Study 1, we also obtained parallel measures from a partner perspective, assessing participants' experiences as partner, rather than as target. In the Auxiliary Analyses section following Study 4, we report findings from across-partner analyses that employ the partnerperspective measures. For now, it is useful to note that for each construct for which we obtained reports from both target and partner perspectives, we assessed the validity of our data by examining the association between measures of parallel constructs. In their self-report questionnaire measures, partners exhibited moderate agreement in their descriptions of partner affirmation $(\beta=.37, p<.01$; e.g., his report of her affirmation with her report of her affirmation), target movement toward ideal $(\beta=.46, p<.01$; e.g., his report of his movement with her report of his movement), and dyadic adjustment $(\beta=.66, p<.01)$. Moreover, participants' self-report measures of partner affirmation, target movement toward ideal, and couple well-being were associated with parallel friend-report measures (described below; $\beta \mathrm{s}=.16, .23$, and .33 , respectively; all $\mathrm{ps}<.01$ ) and with parallel daily diary measures (described below; $\beta \mathrm{s}=.31, .23$, and .40 , respectively; all $p \mathrm{~s}<.01)$.
} 
simple associations of ideal and actual similarity with each criterion, as assessed using self-report variables (see the upper portion of Table 2), friend-report variables (middle portion), and daily diary variables (lower portion). To summarize the resultant 36 analyses, we report mean coefficients from two separate analyses, averaging values across analyses for similarity indices that employ target versus partner ratings of partner attributes (see Table 2, $\beta \mathrm{s}$ under Simple Associations). These analyses revealed that model criteria are fairly reliably associated with both ideal similarity (nine of nine effects for indices using target ratings of partner attributes, eight of nine effects for indices using partner ratings) and actual similarity (eight of nine effects for indices using target ratings of partner attributes, nine of nine effects for indices using partner ratings).

To examine the unique variance attributable to ideal and actual similarity, we regressed each criterion, in turn, simultaneously onto judgment-task indices of ideal and actual similarity (separately for indices using target and partner ratings of partner attributes). To summarize the resultant 36 findings, we report mean

Table 2

Associations of Judgment Task Indices of Ideal Similarity and Actual Similarity With Partner Affirmation, Target Movement Toward the Ideal Self, and Couple Well-Being, Study 2

\begin{tabular}{|c|c|c|c|c|}
\hline \multirow[b]{2}{*}{ Variable } & \multicolumn{2}{|c|}{ Simple associations } & \multicolumn{2}{|c|}{ Regression results } \\
\hline & $\begin{array}{l}\text { Ideal } \\
\text { similarity }\end{array}$ & $\begin{array}{l}\text { Actual } \\
\text { similarity }\end{array}$ & $\begin{array}{l}\text { Ideal } \\
\text { similarity }\end{array}$ & $\begin{array}{l}\text { Actual } \\
\text { similarity }\end{array}$ \\
\hline \multicolumn{5}{|c|}{ Self-report questionnaire criteria } \\
\hline Partner affirmation (SR) & $.28^{* * *}$ & $.27^{* * *}$ & $.21^{* * *}$ & $.14^{\dagger}$ \\
\hline $\begin{array}{l}\text { Target movement toward } \\
\text { ideal (SR) }\end{array}$ & $.25^{* *}$ & $.24^{* * *}$ & $.18^{*}$ & $.14^{\dagger}$ \\
\hline Dyadic adjustment (SR) & $.20^{* *}$ & $.20^{* * *}$ & $.13^{*}$ & $.12^{\dagger}$ \\
\hline \multicolumn{5}{|c|}{ Friend-report questionnaire criteria } \\
\hline Partner affirmation (FR) & $.25^{* *}$ & $.28^{* * *}$ & .10 & $.22^{*}$ \\
\hline $\begin{array}{l}\text { Target movement toward } \\
\text { ideal (FR) }\end{array}$ & $.26^{* * *}$ & $.20^{* * *}$ & $.22^{*}$ & .05 \\
\hline Dyadic adjustment (FR) & $.23^{* * *}$ & $.25^{* * *}$ & $.16^{*}$ & $.16^{\dagger}$ \\
\hline \multicolumn{5}{|c|}{ Daily diary criteria } \\
\hline Partner affirmation (DD) & $.15^{* *}$ & $.16^{*}$ & $.17^{*}$ & .07 \\
\hline $\begin{array}{l}\text { Target movement toward } \\
\text { ideal (DD) }\end{array}$ & $.13^{*}$ & .10 & $.14^{\dagger}$ & .01 \\
\hline $\begin{array}{l}\text { Satisfaction with } \\
\text { relationship (DD) }\end{array}$ & $.14^{* * *}$ & $.18^{* * *}$ & .07 & $.14^{\dagger}$ \\
\hline
\end{tabular}

Note. $\quad \mathrm{SR}=$ self-report questionnaire variables; FR $=$ friend-report questionnaire variables; DD = daily diary variables. Statistics listed under simple associations are the simple association of ideal similarity and actual similarity with each criterion, and statistics under regression results are coefficients from two-factor regression analyses; statistics for both types of analysis are the means of two separate hierarchical linear modeling analyses, averaging values across analyses for similarity indices that employ target versus partner ratings of partner attributes. Analyses were based on data from 60 to 129 couples (degrees of freedom for self-report criteria ranged from 128 to 129 ; degrees of freedom for friend-report criteria ranged from 58 to 59; degrees of freedom for daily diary criteria ranged from 105 to 106); $N$ varies across analyses because of differences in the number of participants versus friends who took part in the study, as well as because of missing data for some variables.

${ }^{\dagger} p<.10 .{ }^{*} p<.05 . \quad{ }^{* * *} p<.01$. coefficients from two separate analyses, averaging values across analyses for similarity indices that employ target versus partner ratings of partner attributes (see Table 2, $\beta$ s under Regression Results). Our two-factor analyses revealed that ideal similarity accounts for significant or marginal unique variance in seven of nine analyses; actual similarity accounts for significant or marginal unique variance in six of nine analyses. (We replicated these analyses including Ideal Similarity $\times$ Actual Similarity interaction terms; only 3 of 18 interaction effects were even marginally significant.)

The unique variance attributable to ideal similarity and actual similarity tends to be low because these variables are correlated, for indices using both target and partner ratings of partner attributes $(\beta s=.69$ and .63 , respectively; both $p$ s $<.01)$. Nevertheless, these findings are striking in that (a) the anticipated simple associations with ideal similarity are reliably evident for quite indirect judgment-task indices (nine of nine effects); (b) the predicted associations with ideal similarity tend to be evident beyond variance attributable to actual similarity, despite the fact that these variables are correlated (seven of nine effects); (c) such associations are evident not only for self-report questionnaire criteria but also for daily diary criteria obtained during a specific 8-day period; and (d) such associations were also evident in across-person analyses that examined the association of participant-report variables with friend-report criteria.

In addition to examining the associations of ideal and actual similarity with each criterion, we examined the associations among partner affirmation, target movement toward ideal, and couple well-being. These analyses revealed patterns of association that are consistent with our broader model (see Figure 1): Partner affirmation is associated with target movement toward ideal (for selfreport criteria, friend-report criteria, and daily diary criteria, $\beta \mathrm{s}=$ $.37, .48$, and .47 , respectively; all $p \mathrm{~s}<.01$ ), and target movement toward ideal is associated with couple well-being (for self-report criteria, friend-report criteria, and daily diary criteria, $\beta_{\mathrm{s}}=.22$, .43 , and .36 , respectively; all $p s<.01)$. We return to these findings in the Auxiliary Analyses section that follows Study 4, in a meta-analytic review of results regarding direct and indirect effects.

Mediation analyses. As in Study 1, we also performed mediation analyses to assess the plausibility of our claims about why ideal similarity is beneficial (controlling for actual similarity). To simplify these analyses, we report findings for the judgment-task indices using target ratings of partner attributes. Consistent with predictions, Sobel's tests revealed that (a) the association of ideal similarity with target movement toward ideal was wholly mediated by partner affirmation (for self-report and diary criteria, $z \mathrm{~s}=2.98$ and 2.67, respectively; both $p s<.01$ ), (b) the association of ideal similarity with couple well-being was wholly mediated by partner affirmation (for self-report and diary criteria, $z \mathrm{~s}=3.29$ and 2.65, respectively; both $p \mathrm{~s}<.01$ ), and (c) the association of ideal similarity with couple well-being was partially to wholly mediated by target movement (for self-report, friend-report, and diary criteria, $z \mathrm{~s}=2.21,2.65$, and 2.19, respectively; all $p \mathrm{~s}<.03$ ). We could not assess mediation for two models involving friend reports of partner affirmation because ideal similarity did not account for unique variance beyond actual similarity.

Why is partner similarity beneficial? We also explored whether each of six mechanisms might explain the observed as- 
sociations of ideal similarity with partner affirmation and with target movement toward the ideal self. For the sake of simplicity, we report findings for the judgment-task indices using target ratings of the partner and examine mediation for self-report measures of model criteria. First, we examined the simple association of each mechanism with partner affirmation; all associations were significant (see Table 3, $\beta$ s under Partner Affirmation). Next, we regressed each mechanism, in turn, simultaneously onto the judgment-task indices of ideal similarity and actual similarity; in the prediction of each mechanism, ideal similarity accounted for unique variance beyond actual similarity (see Table 3, $\beta$ s under Ideal Similarity). And finally, we performed mediation analyses to assess whether each mechanism plausibly mediates the associations of ideal similarity with partner affirmation and with target movement toward ideal (controlling for actual similarity); each mechanism mediated the association of ideal similarity with partner affirmation, and each mechanism mediated the association of ideal similarity with target movement toward the ideal self (see Table 3, zs under Affirmation and Movement). ${ }^{7}$ And finally, we regressed each criterion simultaneously onto all six mechanisms to determine which were the most important mechanisms underlying the Michelangelo process. These analyses revealed that (a) four mechanisms account for unique variance in partner affirmation (partner believes in target's potential, partner is skilled at affirmation, partner challenges target, and partner is responsive), and (b) three mechanisms account for unique variance in target movement toward ideal (belief in target's potential, skill at affirmation, and

Table 3

Mechanisms Underlying the Association of Ideal Similarity With Partner Affirmation and Target Movement Toward Ideal,

Study 2

\begin{tabular}{|c|c|c|c|c|}
\hline \multirow[b]{2}{*}{ Mechanism } & \multirow{2}{*}{$\begin{array}{c}\text { Partner } \\
\text { affirmation }\end{array}$} & \multirow{2}{*}{$\begin{array}{c}\text { Ideal } \\
\text { similarity }\end{array}$} & \multicolumn{2}{|c|}{$\begin{array}{l}\text { Mediation of ideal } \\
\text { similarity effects }\end{array}$} \\
\hline & & & Affirmation & Movement \\
\hline $\begin{array}{l}\text { Partner is dedicated to } \\
\text { target's ideals }\end{array}$ & $.55^{* *}$ & $.33^{* *}$ & $3.98^{* * *}$ & $3.65^{* * *}$ \\
\hline $\begin{array}{l}\text { Partner believes in } \\
\text { target's potential }^{\mathrm{a}}\end{array}$ & $.57^{* *}$ & $.24^{* * *}$ & $3.01^{* *}$ & $2.88^{* * *}$ \\
\hline $\begin{array}{l}\text { Partner is skilled at } \\
\text { affirmation }^{\mathrm{a}}\end{array}$ & $.56^{* *}$ & $.25^{* *}$ & $3.13^{* *}$ & $3.03^{* *}$ \\
\hline $\begin{array}{l}\text { Partner challenges } \\
\text { target }^{\mathrm{a}}\end{array}$ & $.64^{* *}$ & $.29^{* *}$ & $3.79^{* *}$ & $3.59^{* * *}$ \\
\hline $\begin{array}{l}\text { Partner offers ideal- } \\
\text { pursuit strategies }\end{array}$ & $.47^{* *}$ & $.24^{* * *}$ & $2.77^{* *}$ & $2.70^{* * *}$ \\
\hline Partner is responsive $\mathrm{e}^{\mathrm{a}}$ & $.60^{* *}$ & $.38^{* * *}$ & $4.66^{* *}$ & $3.78^{* * *}$ \\
\hline
\end{tabular}

Note. Statistics listed under partner affirmation are the simple associations of each mechanism with partner affirmation; statistics under ideal similarity are the associations of each mechanism with ideal similarity, controlling for actual similarity. Statistics under mediation of ideal similarity effects are Sobel's tests examining the ability of each mechanism to mediate the association of ideal similarity with partner affirmation (controlling for actual similarity; under affirmation) and target movement toward ideal (under movement). Analyses are based on data from 129 couples (degrees of freedom for analyses ranged from 126 to 128).

${ }^{a}$ In simultaneous regressions of all mechanisms onto each criterion, mechanism accounts for unique variance in partner affirmation and/or self movement toward ideal.

*** $p<.01$. challenging the target; see Table 3 , mechanisms noted with a superscript $a$ ).

\section{Discussion}

Study 2 revealed further support for the claim that when partners possess key elements of one another's ideal selves, partners are more affirming of one another, each person experiences greater movement toward his or her ideal self, and the couple enjoys greater adjustment. Ideal similarity exhibited fairly consistent associations with model criteria, and mediation analyses supported the claim that the benefits of ideal similarity are at least partially attributable to Michelangelo process variables. Also, associations with ideal similarity do not appear to be attributable to actual similarity: Ideal similarity fairly reliably accounted for unique variance beyond actual similarity. In addition, analyses examining mechanisms of affirmation revealed that partners who possess important elements of our ideal selves may exhibit greater affirmation because they believe in our potential, are more skilled at affirmation, challenge us to do our very best, and are generally responsive with respect to our goal pursuits. Our confidence in these findings is enhanced by the fact that we observed support for our hypotheses (a) in analyses employing indices of similarity based on quite indirect judgment tasks, using both target and partner ratings of partner attributes, and (b) in analyses employing criteria assessed using self-report variables, friend-report variables, and daily diary variables.

Consistent with the line of speculation outlined in the introduction, Study 2 provides the first empirical evidence that actual similarity may contribute to couple satisfaction and adjustment in part because it promotes the Michelangelo process: Actual similarity frequently accounted for unique variance in model variables beyond ideal similarity, and analyses examining mechanisms revealed that partners who possess important elements of our actual selves may exhibit greater affirmation (and promote our movement toward ideal) because they are dedicated to our ideals, challenge us to do our very best, and offer good strategies for achieving our ideals. Moreover, Study 2 revealed that diverse indices of ideal similarity and actual similarity tend to be positively correlated; that is, people tend to be involved with partners who resemble both their actual selves and their ideal selves.

\section{Study 3}

Studies 1 and 2 revealed good support for the predicted associations of ideal similarity with model variables, and Study 2 revealed that ideal similarity typically accounts for unique variance beyond actual similarity. As such, it would appear that ideal similarity indeed shapes the manner in which close partners influence one another's goal pursuits. However, given that ideal similarity and actual similarity were correlated in Study 2, in Study 3, we independently manipulated these variables. Our procedure was

\footnotetext{
${ }^{7}$ Actual similarity accounted for unique variance beyond ideal similarity for three of six mechanisms: partner is dedicated to ideals, partner challenges target, and partner offers ideal-pursuit strategies $(\beta s=.13, .16$, and .18 , respectively; all $\mathrm{ps}<.09$ ). Mediation analyses revealed significant or marginal mediation of actual similarity effects by each of these mechanisms ( $z$ s ranged from 1.69 to 2.17 ; all $p \mathrm{~s}<.10$ ).
} 
predicated on the assumption that people hold cognitive representations of the actual self and the ideal self, such that it should be possible to prime thoughts about a potential dating partner who is low versus high in actual and ideal similarity. Following the priming of a potential dating partner, we asked participants to make judgments regarding two Michelangelo process variables (partner's capacity for affirmation, own capacity for movement) and two relational quality variables (attraction to partner, pleasantness of interaction). We hypothesized that (a) in comparison with participants in the low-ideal-similarity condition, those in the high-ideal-similarity condition would exhibit higher ratings for Michelangelo process variables and relational variables, and (b) the effects of ideal similarity on relational variables would be mediated by Michelangelo variables. Following Study 2 findings regarding actual similarity, we also examined whether (c) actual similarity might also influence Michelangelo variables and relational variables, and (d) if so, by what process (e.g., are the effects of actual similarity on relational variables mediated by Michelangelo process variables?).

\section{Method}

Participants. Participants were 160 individuals (92 women, 68 men) who were recruited on the campus of the Vrije Universiteit Amsterdam, Amsterdam, the Netherlands. Participants were 19.89 years old, on average $(S D=2.35)$; the majority were students at the university (94\%). Most participants were Dutch (98\%); the experiment was conducted in Dutch. Participants took part in the experiment in groups ranging in size from 1 to 6 individuals. Upon arrival at the research session, participants were randomly assigned to one of four experimental conditions (High vs. Low Actual Similarity $\times$ High vs. Low Ideal Similarity). Participants were paid $€ 3.50$ (about $\$ 4.84$ ) for taking part in the study.

Procedure. Participants were recruited via announcements posted on the campus of the Vrije Universiteit. The study was described as an exploration of initial attraction. First, participants completed three personality scales (described in Footnote 9). Then we presented a 5-min priming experience that activated thoughts about a potential dating partner who was low or high in actual similarity and low or high in ideal similarity. The prime was delivered under conditions designed to maximize focus and minimize distraction: Participants were seated in separate cubicles, were facing large computer screens, and wore headphones. The priming experience was delivered both (a) orally, via a tape recording of a male voice, and (b) visually, via the simultaneous display of this information on the computer screen, sentence by sentence. There were periodic pauses during which participants were asked to envision the primed partner.

Over the course of the 5-min priming experience, we activated thoughts about a potential dating partner whom the participant met at a party and with whom he/she conversed about varied topics (this information was constant across conditions): "Imagine meeting a person at a party ... You are getting to know the person ... Imagine that the person is right there with you ... Time is passing; you have to leave soon ... The person suggests that the two of you meet for a beer or coffee sometime ... Imagine spending more time with this person." Over the course of the priming sequence, we manipulated low versus high actual similarity (actual similarity priming information was always presented first): "the person is a lot like [not much like] what you're like ... you actually have [do not have] much in common." We also manipulated low versus high ideal similarity: "this person seems to be [doesn't seem to be] the kind of person you hope to become someday ... the person has a lot of traits that you'd really like [wouldn't like] to have yourself and seems to be good at things you'd like to be good at [you don't care about]."

Then participants made judgments about the primed partner, rating (a) two Michelangelo process variables - partner capacity for affirmation (two items; e.g., "This person would treat me in a way that is close to the person I ideally would like to be"; for all items, $0=$ do not agree at all, $8=$ agree completely; $\alpha=.66$ ) and own capacity for movement toward ideal (three items; e.g., "This person would help bring out the best side of me"; $\alpha=.79$ ), and (b) two relational quality variables - attraction to partner (three items; e.g., "I think I could really like this person"; $\alpha=.77$ ) and predicted pleasantness of interaction (three items; e.g., "I would expect the meeting with this person to be pleasant"; $\alpha=.78)$. We also included measures to assess the effectiveness of our manipulations, including perceived actual similarity (four items; e.g., "I feel that this person is very similar to me at this point in my life"; $\alpha=.81$ ) and perceived ideal similarity (four items; e.g., "This person seems to have the qualities that I seek for myself"; $\alpha=$ .90). Finally, we assessed involvement in the study and perceptions regarding the purpose of the study. Participants were interested in the potential partner and believed that the study indeed concerned initial attraction but were unaware of the fact that the experiment examined the effects of actual or ideal similarity. At the end of the session, participants were paid and thanked for their assistance.

\section{Results}

Analysis strategy. We initially performed four-factor analyses of variance (ANOVAs) on all dependent variables, the independent variables being low versus high ideal similarity, low versus high actual similarity, participant gender, and relationship status (whether participants were presently involved vs. not presently involved with a dating partner; $42 \%$ were presently involved). Fewer than $6 \%$ of the effects involving gender and/or relationship status were significant, so we dropped these variables from the analyses. Table 4 presents means for each dependent variable as a function of low versus high ideal similarity and low versus high actual similarity.

Manipulation checks. Two-factor ANOVAs performed on our manipulation checks revealed that participants in the high-idealsimilarity condition perceived that the primed partner exhibited greater similarity to their ideal selves than did those in the lowideal-similarity condition ( $M \mathrm{~s}=5.04$ and 2.54, respectively), $F(1$, $156)=107.55, p<.01$, and that participants in the high-actualsimilarity condition perceived that the primed partner exhibited greater similarity to their actual selves than did those in the low-actual-similarity condition $(M \mathrm{~s}=4.63$ and 2.74, respectively), $F(1,156)=78.57, p<.01$. However, across-manipulation effects were also evident: Actual similarity also affected perceived ideal similarity, $F(1,156)=16.23, p<.01$, and ideal similarity also affected perceived actual similarity, $F(1,156)=22.74, p<$ .01 . Thus, and as might be anticipated given that ideal similarity and actual similarity often are correlated (see Study 2), each manipulation exerted fairly strong manipulation-specific effects 
(for ideal and actual similarity, $\beta \mathrm{s}=.68$ and .55 , respectively), as well as weaker across-manipulation effects $(\beta \mathrm{s}=.29$ and .30 , respectively).

Predicting key model variables. Consistent with predictions, two-factor ANOVAs revealed that ideal similarity exerted significant effects on both Michelangelo process variables and relational variables, with participants in the high-ideal-similarity condition reporting greater partner capacity for affirmation, own capacity for movement toward ideal, attraction to the partner, and predicted pleasantness of interaction (see means in Table 4$), F \mathrm{~s}(1,156)=$ $11.35,53.39,39.16$, and 35.48, respectively, all $p$ s $<.01$. Moreover, actual similarity also exerted significant effects on all four criteria, with participants in the high-actual-similarity condition reporting higher scores for all four variables, $F \mathrm{~s}(1,156)=8.36$, $15.70,13.83$, and 20.65, respectively, all $p s<.01$. No Ideal Similarity $\times$ Actual Similarity interactions were significant. Moreover, tests of simple effects revealed that ideal similarity influenced all four dependent variables, irrespective of actual similarity level: Ideal similarity effects were significant under conditions of both high actual similarity, $F \mathrm{~s}(1,156)=7.71,15.67,12.17$, and 15.12 , respectively, all $p \mathrm{~s}<.01$, and low actual similarity, $F_{\mathrm{S}}(1$, $156)=3.95,40.64,28.74$, and 20.58, respectively, all $p s<.05$.

Recall that our similarity manipulations exerted acrossmanipulation effects: Ideal similarity influenced perceived actual similarity, and actual similarity influenced perceived ideal similarity. To determine if ideal and actual similarity exert unique effects, we regressed each dependent variable simultaneously onto the manipulation check measures of perceived ideal similarity and perceived actual similarity. As anticipated, perceived ideal similarity accounted for significant unique variance for all four criteria ( $\beta s=.30, .52, .40$, and .34 , respectively, all $p \mathrm{~s}<.01)$; parallel unique effects were observed for perceived actual similarity ( $\beta \mathrm{s}=$ $.34, .29, .40$, and .42 , respectively, all $p \mathrm{~s}<.01$ ).

Exploring alternative interpretations. If the primed partner was more attractive or socially desirable in the high-idealsimilarity and/or the high-actual-similarity conditions, the observed effects on Michelangelo process variables might be attributable to demand characteristics or to global attraction to the partner. To explore this possibility, we regressed each Michelangelo process variable onto perceived ideal similarity, perceived actual similarity, and our measure of attraction to the partner. The association of ideal similarity with Michelangelo variables re- mained significant for judgments regarding partner capacity for affirmation and own capacity for movement toward ideal ( $\beta \mathrm{s}=$ .14 and .27 , respectively; both $p s<.04)$. The associations with actual similarity remained significant for judgments regarding partner capacity for affirmation $(\beta=.21, p<.01)$ but not for own capacity for movement $(\beta=.09, n s)$. We observed parallel findings when we controlled for predicted pleasantness of interaction ( $\beta \mathrm{s}=.17, .31, .22$, and .09 , respectively; three of four $p \mathrm{~s}<.01$ ). Thus, the observed associations of ideal and actual similarity with Michelangelo process variables do not appear to be attributable to generalized attraction; these effects typically are evident even when we control for attraction to the partner.

Mediation analyses. We performed mediation analyses to determine whether the effects of ideal and actual similarity on measures of relational quality were mediated by Michelangelo variables. Consistent with hypotheses, the effects of ideal similarity on attraction to the primed partner and predicted pleasantness of interaction (controlling for actual similarity) were significantly mediated by judgments regarding the partner's capacity for affirmation $(z \mathrm{~s}=2.99$ and 2.88 , respectively; both $p \mathrm{~s}<.01)$ and by judgments regarding the participant's own capacity for movement toward ideal $(z \mathrm{~s}=6.11$ and 6.02 , respectively; both $p \mathrm{~s}<.01)$. In addition, the effect of ideal similarity on judgments of own capacity for movement was mediated by partner capacity for affirmation $(z=3.09, p<.01)$. Consistent with the line of speculation outlined in the introduction, parallel analyses performed for actual similarity revealed that actual similarity may contribute to relational quality in part because it promotes the Michelangelo process: The effects of actual similarity on attraction to the primed partner and predicted pleasantness of interaction (controlling for ideal similarity) were mediated by judgments regarding partner capacity for affirmation ( $z \mathrm{~s}=2.65$ and 2.57 , respectively; both $p \mathrm{~s}<.02)$ and own capacity for movement toward ideal $(z \mathrm{~s}=3.74$ and 3.72, respectively; both $p$ s $<.01$ ). In addition, the effect of actual similarity on own capacity for movement was mediated by partner capacity for affirmation $(z=2.71, p<.01)$.

\section{Discussion}

Study 3 revealed that when an experimentally primed partner resembles the target's ideal self, targets judge that the partner possesses a greater capacity for affirmation, judge that they have a

Table 4

Mean Partner Capacity for Affirmation, Target Capacity for Movement Toward Ideal, Attraction to Partner, and Predicted Pleasantness of Interaction, Study 3

\begin{tabular}{|c|c|c|c|c|c|c|c|c|}
\hline \multirow[b]{3}{*}{ Variable } & \multicolumn{4}{|c|}{ High ideal similarity } & \multicolumn{4}{|c|}{ Low ideal similarity } \\
\hline & \multicolumn{2}{|c|}{$\begin{array}{c}\text { High actual } \\
\text { similarity }\end{array}$} & \multicolumn{2}{|c|}{$\begin{array}{l}\text { Low actual } \\
\text { similarity }\end{array}$} & \multicolumn{2}{|c|}{$\begin{array}{l}\text { High actual } \\
\text { similarity }\end{array}$} & \multicolumn{2}{|c|}{$\begin{array}{l}\text { Low actual } \\
\text { similarity }\end{array}$} \\
\hline & $M$ & $S D$ & $M$ & $S D$ & $M$ & $S D$ & $M$ & $S D$ \\
\hline Partner capacity for affirmation & 5.23 & 1.45 & 4.41 & 1.63 & 4.30 & 1.32 & 3.75 & 1.54 \\
\hline Own capacity for movement toward ideal & 5.58 & 1.26 & 5.06 & 1.40 & 4.29 & 1.51 & 2.99 & 1.60 \\
\hline Attraction to partner & 5.29 & 1.20 & 4.74 & 1.43 & 4.16 & 1.53 & 3.00 & 1.62 \\
\hline Predicted pleasantness of interaction & 5.73 & 1.20 & 4.84 & 1.48 & 4.53 & 1.44 & 3.44 & 1.39 \\
\hline
\end{tabular}

Note. Higher numbers reflect greater levels of each construct (range for each variable $=0-8$ ). Statistics are from two-factor analyses of variance based on data from 160 participants. 
greater capacity for movement toward their ideals, report stronger attraction to the partner, and predict more pleasant interaction with the partner. Mediation analyses revealed that the associations of ideal similarity with both indices of relational quality are attributable to Michelangelo process variables, to judgments regarding partner capacity for affirmation and own capacity for movement toward ideal. Auxiliary analyses revealed that the associations of ideal similarity with Michelangelo process variables are not attributable to generalized attraction to the partner. These results extend findings from Study 2 by experimentally manipulating ideal similarity and actual similarity in the context of a priming experience, thereby increasing the independence of these constructs.

Study 3 results regarding actual similarity replicate traditional findings regarding similarity and attraction: When a primed partner resembles the target's actual self, targets are more attracted to the partner and predict more pleasant interaction with the partner. It is important to note that Study 3 extends previous work by demonstrating that actual similarity may contribute to relational quality in part because it promotes the Michelangelo process: When a primed partner resembles the target's actual self, targets also judge that the partner possesses a greater capacity for affirmation and that they have a greater capacity for movement toward their ideals. Mediation analyses revealed that the associations of actual similarity with indices of relational quality are attributable to Michelangelo process variables, to judgments regarding partner capacity for affirmation and own capacity for movement toward ideal. These results extend the similarity-attraction literature, revealing that actual similarity may serve an interpersonal function, promoting relational quality in part because it promotes partner affirmation and target growth.

\section{Study 4}

Studies 1, 2, and 3 revealed good support for predictions regarding the associations of ideal similarity with Michelangelo model variables. Studies 2 and 3 demonstrated that ideal similarity accounts for unique variance in model criteria beyond actual similarity, and Study 3 demonstrated that both ideal similarity and actual similarity exert causal effects on model criteria. In Study 4, we explored whether partner similarity to one's ideal self is of long-term consequence for relationships. We employed time-series data from two longitudinal studies to evaluate whether ideal similarity predicts changes over a 6-month period in people's experiences of partner affirmation, target movement toward the ideal self, and couple well-being.

\section{Method}

Study 4a: Participants and procedure. The data for Study 4a are from 103 couples who took part in Time 3 and Time 4 activities of the longitudinal study of newly committed couples that we described earlier (see Studies 1 and 2; 101 heterosexual couples, 2 lesbian couples). Time 3 and Time 4 activities were separated by 6 months. Couples were paid $\$ 180$ total for taking part in Time 3 and 4 activities. Participants' demographic characteristics were described in Study 2. We assessed ideal similarity with judgment-task indices using both target and partner ratings of partner attributes $(\alpha \mathrm{s}=.56$ and .53 , respectively; see Study 2 descriptions). In questionnaires completed in connection with
Time 3 and 4 research activities, we obtained self-report measures of partner affirmation (Time 3 and $4 \alpha \mathrm{s}=.89$ and .92 , respectively), target movement toward ideal (Time 3 and $4 \alpha \mathrm{s}=.77$ and .77 , respectively), and dyadic adjustment (Time 3 and $4 \alpha \mathrm{s}=.90$ and .91 , respectively; see Study 2 descriptions).

Study 4b: Participants and procedure. The data for Study $4 \mathrm{~b}$ are from 69 students at Northwestern University who took part in a 6-month longitudinal study of dating relationships (35 women, 34 men). Participants were paid $\$ 100$ for taking part in all components of the study. At Time 1, participants were 18.04 years old, on average $(S D=0.44)$, and had been involved with their dating partners for an average of 13.05 months $(S D=9.76)$. Participants were recruited via announcements posted around the campus of Northwestern University. The requirements for participation were that participants be (a) 1st-year undergraduates at Northwestern, (b) involved in relationships of at least 2 months in duration, (c) between 17 and 19 years of age, (d) native English speakers, and (e) the only member of a given couple to participate in the study.

Participants completed online questionnaires once every 2 weeks over the course of a 6-month period. The questionnaires included items to measure ideal similarity (one item; "My partner already possesses the characteristics that I would like to acquire to approach my ideal self"; for all items, $1=$ disagree strongly, $7=$ agree strongly), partner affirmation of self (one item; "My partner behaves toward me as if I already possess the characteristics of my ideal self"), self-movement toward ideal (one item; "I am making good progress toward becoming my "ideal self"'), and relationship commitment (one item; "I am committed to maintaining this relationship in the long-run"). Twenty-six participants broke up with their partners during the study; in the analyses reported below, we include data regarding their relationships prior to the time of breakup. At the end of the study, participants were debriefed, paid, and thanked for their assistance.

\section{Results}

Analysis strategy. As in Studies 1 and 2, given that the data from two partners in a relationship are nonindependent (Study 4a), as are the data provided by a given individual on multiple occasions (both studies), we analyzed our data using hierarchical linear modeling. Our analyses included three levels of nesting in Study 4a (data from multiple research occasions were nested within individuals; data from partners were nested within couples) and included two levels of nesting in Study $4 \mathrm{~b}$ (data from multiple research occasions were nested within individuals). We represented intercepts as random effects and represented slopes as fixed effects. Initial analyses included gender as an independent variable; fewer than $10 \%$ of the effects involving gender were significant, so we dropped this variable from the analyses.

Predicting key model variables. We performed residualized lagged analyses to examine whether earlier ideal similarity predicts change over time in each criterion, regressing later measures of each criterion onto earlier measures of ideal similarity, controlling for earlier levels of the criterion. In Study 4a, we employed judgment-task indices of ideal similarity using both target and partner ratings of partner attributes. As hypothesized, earlier ideal similarity predicts significant or marginal change over time in partner affirmation, target movement toward ideal, and couple 
well-being (see Table 5). These associations were evident in Study 4a analyses employing a judgment-task index of ideal similarity that used target ratings of partner attributes (three of three effects), in Study 4a analyses employing a judgment-task index that used partner ratings of partner attributes (three of three effects), and in Study $4 \mathrm{~b}$ analyses (three of three effects).

In Study $4 b$, we were able to examine an additional index of couple well-being: relationship persistence versus breakup (in Study $4 \mathrm{a}$, there were too few breakups to perform this analysis). We represented persistence versus breakup as a person-level variable (1 vs. 0), regressing ideal similarity onto this variable. As anticipated, mean level of ideal similarity was greater in relationships that persisted than in relationships that ended (see Figure 2), $t(648)=2.34, p<.02$.

We also examined the associations among partner affirmation, target movement toward ideal, and couple well-being. These analyses revealed associations that are consistent with our model: In both studies, partner affirmation predicted significant change over time in target movement toward ideal $(\beta \mathrm{s}=.14$ and .11 , respectively; both $p s<.01$ ), and in Study $4 \mathrm{~b}$, target movement toward ideal predicted marginal change over time in couple well-being $(\beta=.05, p<.07$; Study $4 \mathrm{a} \beta=.02, n s){ }^{8}$

Table 5

Residualized Lagged Analyses Predicting Partner Affirmation, Movement Toward the Ideal Self, and Couple Well-Being, Studies $4 a$ and $4 b$

\begin{tabular}{|c|c|c|c|}
\hline Variables & $\beta$ & $t$ & $p<$ \\
\hline \multicolumn{4}{|c|}{$\begin{array}{l}\text { Study 4a: Longitudinal study of newly committed couples: Judgment- } \\
\text { task index employing target ratings of partner attributes }\end{array}$} \\
\hline $\begin{array}{l}\text { Earlier ideal similarity }(\mathrm{JT}-\mathrm{TR}) \rightarrow \text { Later } \\
\quad \text { partner affirmation }(\mathrm{SR})\end{array}$ & .20 & 3.63 & .01 \\
\hline $\begin{array}{l}\text { Earlier ideal similarity (JT-TR) } \rightarrow \text { Later } \\
\quad \text { target movement }(\mathrm{SR})\end{array}$ & .20 & 3.67 & .01 \\
\hline $\begin{array}{l}\text { Earlier ideal similarity }(\mathrm{JT}-\mathrm{TR}) \rightarrow \text { Later } \\
\text { dyadic adjustment }(\mathrm{SR})\end{array}$ & .08 & 2.15 & .03 \\
\hline
\end{tabular}

Study 4a: Longitudinal study of newly committed couples: Judgmenttask index employing partner ratings of partner attributes

Earlier ideal similarity (JT-PR) $\rightarrow$ Later partner affirmation (SR)

target movement (SR)
Earlier ideal similarity (JT-PR) $\rightarrow$ Later $\begin{array}{lll}.15 & 2.73 \quad .01\end{array}$ dyadic adjustment (SR)

$\begin{array}{lll}.18 & 3.24 \quad .01\end{array}$

$\begin{array}{lll}.15 & 3.90 \quad .01\end{array}$

Study 4b: Longitudinal study of freshman dating realtionships

Earlier ideal similarity (SR) $\rightarrow$ Later partner affirmation (SR)

Earlier ideal similarity (SR) $\rightarrow$ Later

target movement (SR)
Earlier ideal similarity (SR) $\rightarrow$ Later commitment level (SR)

\begin{tabular}{lll}
.11 & 2.48 & .02 \\
.08 & 1.90 & .06 \\
.08 & 3.07 & .01 \\
\hline
\end{tabular}

Note. JT-TR and JT-PR $=$ judgment-task indices employing target and partner ratings of partner attributes, respectively; SR = self-report questionnaire variables. Statistics are from residualized lagged hierarchical linear modeling analyses. Study 4a analyses are based on data from 103 couples (degrees of freedom for all analyses were 101); Study 4b analyses are based on data from 67 to 69 individuals (degrees of freedom for analyses ranged from 578 to 595); $N$ varies across analyses because of missing data for some variables.

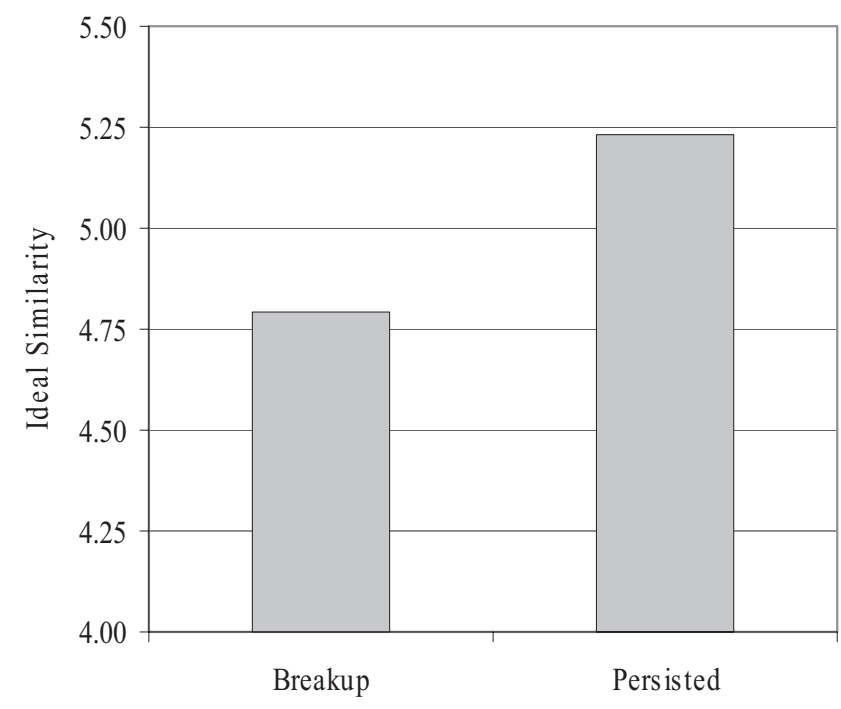

Figure 2. Mean ideal similarity in relationships that persisted versus ended, Study $4 \mathrm{~b}$.

\section{Discussion}

Studies $4 \mathrm{a}$ and $4 \mathrm{~b}$ complement Studies 1 through 3, demonstrating that ideal similarity reliably predicts change over time in Michelangelo model variables. Ideal similarity predicted changes over a 6-month repeated assessment in Study 4a and over multiple 2-week repeated assessments in Study $4 b$. Thus, to the extent that a partner possesses key elements of the target's ideal self, over time, the partner exhibits increasing affirmation of the target's ideals, the target enjoys increasing movement toward his or her ideal self, and the partners experience increasing relationship quality. Moreover, Study 4b revealed higher mean levels of ideal similarity in relationships that persisted over time than in relationships that ended.

\section{Auxiliary Analyses}

We performed a series of auxiliary analyses to further explore our data. These analyses address three broad issues: First, we report findings from analyses that examine across-partner associations for Studies 1 and 2. Next, we report a series of analyses designed to help rule out alternative explanations of our findings. And finally, we present a meta-analytic summary of all direct and indirect associations among model variables.

\section{Across-Partner Associations Among Model Variables, Studies 1 and 2}

To provide even more stringent tests of our predictions, we performed a series of across-partner analyses. Of course, we have already reported several across-person analyses, including the as-

\footnotetext{
${ }^{8}$ We also sought to perform residualized lagged mediation analyses, but after controlling for earlier levels of each criterion, minimal variance remained to be explained by proximal and distal predictors. Thus, because of insufficient change in our criteria, we were unable to evaluate mediation.
} 
sociations of self-reported predictors with both coder-rated criteria (Study 1) and friend-reported criteria (Study 2; see Tables 1 and 2). However, other findings for Studies 1 and 2 were within-person analyses; for self-report variables (both studies), participant ratings of interaction (Study 1), and daily diary measures (Study 2), we assessed model criteria from a target-based perspective, measuring perceived partner affirmation (how affirming is my partner of me?), target movement toward ideal (how well am I achieving my goals?), and couple well-being (see Tables 1 and 2). For each of these measurement methods we also assessed model criteria from a partner-based perspective (i.e., as partner, rather than as target), measuring partner affirmation (how affirming am I of my partner?), perceived target movement toward ideal (how well is my partner achieving his or her goals?), and couple well-being (see Footnotes 4 and 6).

Using these partner-perspective measures, we performed auxiliary across-partner model tests. For each first-order association displayed in Figure 1, we (a) regressed each criterion as reported by the partner (partner-based perspective) onto each predictor as reported by the target (target-based perspective) and (b) regressed each criterion as reported by the target onto each predictor as reported by the partner. We could not perform the target-criterionwith-partner-predictor analyses for ideal similarity because we did not obtain a partner-perspective measure of ideal similarity. In Study 1, we performed separate analyses for self-report questionnaire criteria and participant-interaction rating criteria, and in Study 2, we performed separate analyses for self-report questionnaire criteria and daily diary criteria. Table 6 displays mean statistics for each association, separately for Study 1 and Study 2.

Consistent with predictions, these analyses revealed that targetreported ideal similarity is significantly or marginally associated with partner-reported partner affirmation (e.g., Elizabeth's report of Robert's similarity to her ideal self is associated with Robert's report of his affirmation of Elizabeth). In addition, target-reported perceived partner affirmation is associated with partner-reported perceived target movement toward ideal (e.g., Elizabeth's report of Robert's affirmation of her is associated with Robert's report of Elizabeth's movement toward her ideals), and partner-reported partner affirmation is associated with target-reported target movement (e.g., Elizabeth's report of her affirmation is associated with Robert's report of his movement toward his ideals). And finally, target-reported target movement is associated with partnerreported couple well-being (e.g., Elizabeth's report of her movement is associated with Robert's report of dyadic adjustment), and partner-reported perceived target movement is associated with target-reported couple well-being (e.g., Elizabeth's report of Robert's movement is associated with Robert's report of dyadic adjustment). These findings serve as an important complement to the primary analyses reported earlier, providing particularly rigorous tests of our model.

\section{Exploring Alternative Interpretations}

In the following paragraphs, we report the results of analyses that are designed to help rule out alternative explanations of our findings. We explore possibilities involving inclusion of other in the self, global social support, target idealization of partner, commitment level, partner similarity to the partner's ideals, and socially desirable responding. Unless otherwise indicated, for the sake of simplicity, these analyses employ criterion measures from Study 1, Study 2, and/or Study 4a self-report questionnaires. However, wherever possible, we replicated these analyses using alternative criterion measures (e.g., Study 1 participant ratings or coder ratings, or Study 2 friend reports or daily diary measures). In analyses employing alternative criterion measures, the results reported below were replicated in $86 \%$ of our tests (108 of 126 analyses).

Inclusion of other in the self. Our primary analyses revealed that ideal similarity is associated with greater partner affirmation and target movement toward the ideal self. Are these findings attributable to inclusion of the partner in the self (cf. Aron \& Aron, 2000)? For example, is it possible that when partners possess key elements of the target's ideal self, targets simply incorporate the partner's attributes into the self-thereby enjoying greater movement toward their ideals-without meaningful mediation by partner affirmation? Studies 1, 2, and 4a included the inclusion of other in the self scale, which measures the extent to which people incorporate a partner's attributes into the self (Aron, Aron, \& Smollan, 1992; the scale presents seven Venn diagrams with circles labeled "self" and "partner," depicting varying degrees of self-partner overlap). In turn, we regressed partner affirmation and target movement toward ideal simultaneously onto ideal similarity

Table 6

Across-Partner Associations Among Ideal Similarity, Partner Affirmation, Target Movement Toward the Ideal Self, and Couple Well-Being, Studies 1 and 2

\begin{tabular}{llll}
\hline Variables & $\beta$ & $t$ & $p<$ \\
$\quad$ Study 1: Across-partner associations & & \\
$\quad$ & & & \\
$\quad \begin{array}{l}\text { Ideal similarity (TR) } \rightarrow \text { Partner } \\
\quad \text { affirmation (PR) }\end{array}$ & .09 & 1.73 & .08 \\
$\begin{array}{l}\text { Perceived partner affirmation (TR) } \rightarrow \\
\quad \text { Perceived target movement (PR) }\end{array}$ & .14 & 2.71 & .01 \\
$\begin{array}{l}\text { Partner affirmation (PR) } \rightarrow \text { Target } \\
\text { movement toward ideal (TR) }\end{array}$ & .20 & 3.83 & .01 \\
$\begin{array}{l}\text { Target movement (TR) } \rightarrow \text { Couple } \\
\quad \text { well-being (PR) }\end{array}$ & .14 & 2.88 & .01 \\
$\begin{array}{l}\text { Perceived target movement (PR) } \rightarrow \\
\text { Couple well-being (TR) }\end{array}$ & .14 & 2.95 & .01 \\
\hline
\end{tabular}

Study 2: Across-partner associations

Ideal similarity (TR-JT) $\rightarrow$ Partner affirmation (PR)

Perceived partner affirmation $(\mathrm{TR}) \rightarrow$ Perceived target movement (PR)

Partner affirmation $(\mathrm{PR}) \rightarrow$ Target movement toward ideal (TR)

Target movement (TR) $\rightarrow$ Couple well-being (PR)

Perceived target movement $(\mathrm{PR}) \rightarrow$ Couple well-being (TR)

\begin{tabular}{lll}
.16 & 2.14 & .03 \\
.19 & 2.90 & .01 \\
.19 & 2.97 & .01 \\
.14 & 2.45 & .01 \\
.10 & 2.38 & .02 \\
\hline
\end{tabular}

Note. $\quad \mathrm{TR}=$ target-reported variable (target perspective); $\mathrm{PR}=$ partnerreported variable (partner perspective); TR-JT = judgment-task index (target perspective). Statistics are the means of two separate hierarchical linear modeling analyses, averaging values across analyses for self-report questionnaire criteria and participant interaction rating criteria (Study 1; degrees of freedom for the separate analyses ranged from 177 to 179) or across analyses for self-report questionnaire criteria and daily diary criteria (Study 2; degrees of freedom for the separate analyses ranged from 104 to 127). 
and inclusion of other in the self (controlling for actual similarity in Study 2 and performing a residualized lagged analysis in Study 4a). In all three studies, ideal similarity accounted for unique variance in both partner affirmation $(\beta s=.24, .27$, and .20 , respectively; all $p$ s $<.01)$ and target movement toward ideal $(\beta \mathrm{s}=$ $.25, .31$, and .19, respectively; all $p s<.01$ ). Thus, our results do not appear to be attributable to inclusion of other in the self: The associations of ideal similarity with partner affirmation - and of partner affirmation with target movement toward the ideal self-are evident beyond variance attributable to inclusion of other in the self.

Global social support. Our earlier analyses revealed that partner affirmation is predictive of both target movement toward ideal and couple well-being. Are these findings attributable to the benefits of partner affirmation per se, as we have argued, or might they be attributable to global social support (cf. Sarason, Sarason, \& Gurung, 1997)? For example, is it possible that partners in healthy relationships are simply supportive of one another in a global sense, such that the effects that we wish to attribute to partner affirmation are in fact attributable to global partner support? In Study 1, we assessed global partner support in two ways: First, for each 2-min segment of partners' ideal-relevant interactions, coders rated the extent to which partners were globally supportive of the target ("my partner supported me in pursuing my goal"). Second, for each of their top three ideal self goals, participants provided self-report ratings of both partner affirmation ("My partner says and does things that help me move closer to this goal") and global partner support ("My partner supports me in pursuing this goal"). In turn, we regressed target movement toward ideal and couple well-being simultaneously onto partner affirmation and each measure of global partner support. The coefficients for partner affirmation were significant in all four analyses $(\beta s=.61, .23, .38$, and .13 , respectively; all $p$ s $<.03$ ); coefficients for global partner support were significant for dyadic adjustment ( $\beta \mathrm{s}=.59$ and .28 , respectively; both $p s<.01)$ but not for target movement toward ideal $(\beta s=-.05$ and .04 , respectively; both $n s)$. These findings suggest that the benefits of partner affirmation are not attributable to global partner support: Partner affirmation uniquely predicts target movement toward the ideal self; both partner affirmation and global partner support contribute unique variance to predicting couple well-being.

Idealization of partner. Is it possible that the observed associations of ideal similarity with model variables are attributable to target idealization of the partner? When partners possess key elements of the target's ideal self (e.g., to the extent that the partner meets the target's ideal standards; cf. Simpson, Fletcher, \& Campbell, 2001), do targets idealize their partners such that partners, in turn, exhibit greater partner affirmation, targets exhibit greater movement toward their ideals, and couples exhibit greater wellbeing? In Studies 1, 2, and 4a, the partner's report of idealization by the target was measured using a three-item instrument (e.g., "My partner holds an extraordinarily positive opinion of me"). We regressed each model variable, in turn, simultaneously onto ideal similarity and target idealization of the partner (controlling for actual similarity in Study 2 and performing residualized lagged analyses in Study $4 \mathrm{a})$; ideal similarity remained significantly predictive of partner affirmation $(\beta s=.24, .27$, and .19 , respectively; all $p \mathrm{~s}<.01)$, target movement toward ideal $(\beta \mathrm{s}=.13, .20$, and .19 , respectively; all $p \mathrm{~s}<.01)$, and couple well-being $(\beta \mathrm{s}=.21$, .18 , and .09 , respectively; all $p \mathrm{~s}<.01$ ). Thus, our results do not appear to be attributable to the impact of ideal similarity on idealization of the partner: Ideal similarity predicts model criteria beyond variance attributable to the partner's experience of idealization by the target.

Commitment level. Is it possible that the observed associations of ideal similarity with model variables are attributable to commitment? When partners possess key elements of the target's ideal self (e.g., to the extent that the partner meets the target's ideal standards and/or exceeds the target's comparison level; cf. Simpson et al., 2001; Thibaut \& Kelley, 1959), do targets develop stronger commitment to the partner such that they, in turn, report commensurately greater partner affirmation, target movement toward the ideal self, and couple well-being? In Studies 1, 2, and 4a, we measured commitment using a 15-item instrument (e.g., "I am completely committed to maintaining our relationship"). We regressed each model variable, in turn, simultaneously onto ideal similarity and target commitment level (controlling for actual similarity in Study 2 and performing residualized lagged analyses in Study 4a); in all three studies, ideal similarity remained significantly predictive of partner affirmation $(\beta s=.19, .23$, and .19 , respectively; all $p \mathrm{~s}<.01)$, target movement toward ideal $(\beta \mathrm{s}=$ $.10, .18$, and .18 , respectively; all $p s<.05$ ), and couple well-being ( $\beta \mathrm{s}=.17, .16$, and .09 , respectively; all $p \mathrm{~s}<.03$ ). Thus, our results do not appear to be attributable to the impact of ideal similarity on commitment. The associations of ideal similarity with model criteria are evident beyond variance attributable to target commitment level.

Partner similarity to the partner's ideal self. Are our Study 2 findings attributable to the partner's similarity to the target's ideal self, as we have argued, or might these findings be attributable to the partner's similarity to the partner's own ideal self? For example, is it possible that when partners are closer to their own ideal selves, they experience greater sensitivity to the target's ideals (cf. Higgins, 1997), such that they exhibit greater partner affirmation and targets experience greater movement toward their ideals? We employed Study 2 self-report questionnaire variables to explore this possibility. We developed a measure of partner similarity to the partner's ideal self using the earlier-described procedure that we employed to assess partner similarity to the target's ideal self (using partner report of partner ideals and partner report of partner attributes). In turn, we regressed partner affirmation and target movement toward the ideal self simultaneously onto ideal similarity, actual similarity, and partner similarity to the ideal self. Ideal similarity remained significantly predictive of both partner affirmation and target movement toward the ideal self $(\beta \mathrm{s}=.28$ and .18 , respectively; both $p$ s $<.01)$. Thus, our results do not appear to be attributable to the partner's similarity to the partner's own ideals; the associations of ideal similarity with model criteria are evident beyond variance attributable to this variable.

Socially desirable response tendencies. Are the observed associations of ideal similarity with model variables attributable to socially desirable responding? In Studies 1, 2, and 4a, we measured tendencies toward both self-deception and impression management (Paulhus, 1984). We regressed each model variable, in turn, simultaneously onto ideal similarity, self-deception, and impression management (controlling for actual similarity in Study 2 and performing residualized lagged analyses in Study 4a); ideal similarity remained significantly predictive of partner affirmation $(\beta s=.25, .29$, and .21 , respectively; all $p s<.01)$, target movement toward ideal $(\beta \mathrm{s}=.14, .22$, and .22 , respectively; all $p \mathrm{~s}<$ 


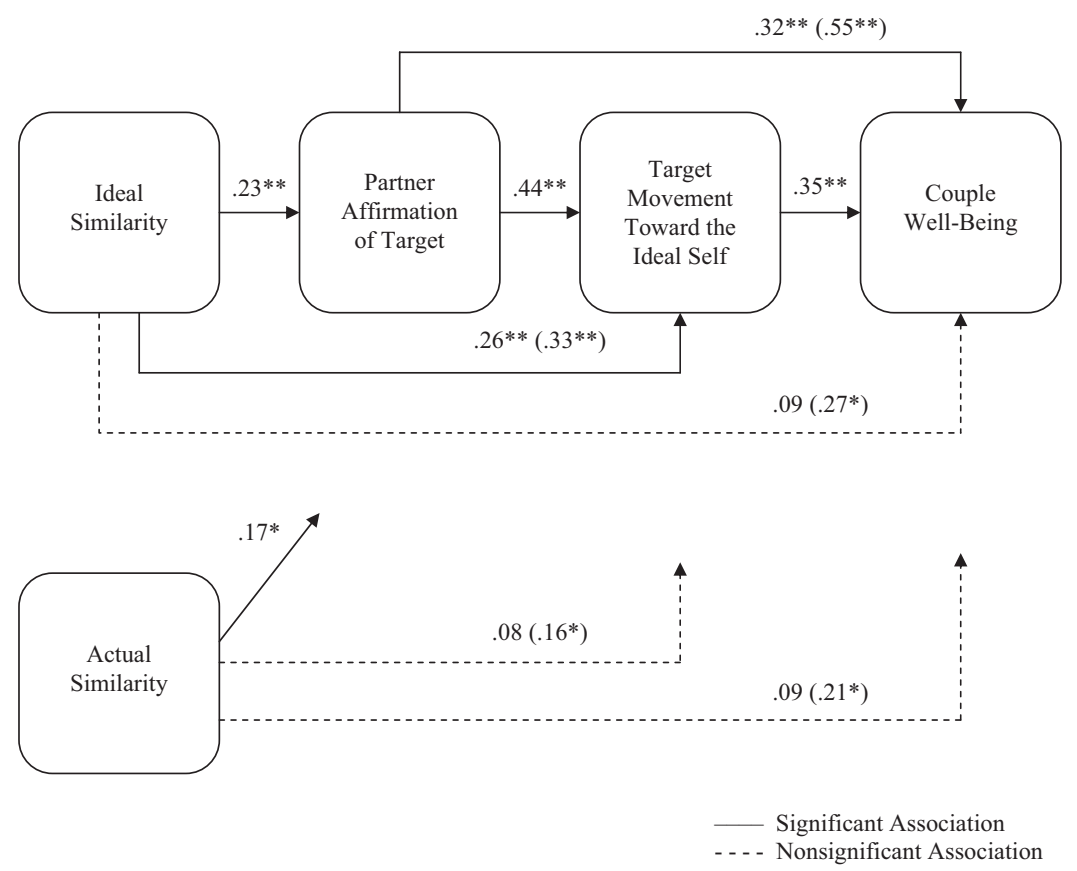

Figure 3. Meta-analysis of the observed associations among ideal similarity, actual similarity, partner affirmation of target, target movement toward the ideal self, and couple well-being, Studies 1, 2, and 3. Estimates for associations with ideal similarity and actual similarity are based on analyses from Studies 2 and 3 that include main effects for both variables as well as their interaction. For indirect effects, simple associations with each criterion are presented in parentheses. ${ }^{*} p<.05 .{ }^{* *} p<.01$.

.01 ), and couple well-being ( $\beta \mathrm{s}=.23, .19$, and .08 , respectively; all $p \mathrm{~s}<.05)$. Thus, our results do not appear to be attributable to socially desirable response tendencies. ${ }^{9}$

\section{Meta-Analytic Summary}

We also sought to estimate all direct and indirect associations among model variables (see Figure 1). Accordingly, in connection with the mediation analyses performed for Studies 1, 2, and 3, we calculated full regression models for each criterion, including as predictors all variables that are represented as proximal or distal causes of each criterion. That is, we regressed (a) couple wellbeing onto target movement toward the ideal self, partner affirmation, and ideal similarity; (b) target movement toward ideal onto partner affirmation and ideal similarity; and (c) partner affirmation onto ideal similarity. In Studies 2 and 3, actual similarity was also included in each model. Rather than laboriously reviewing the models for each criterion (a total of 22 regression models), we calculated a meta-analytic summary of these findings.

Using standardized statistics for each analysis, as well as for all mediation tests, we calculated weighted averages for each statistic, weighting statistics by the sample size for each study. In Study 3, we obtained two measures of relational quality (attraction to partner, predicted pleasantness of interaction); we weighted statistics for these analyses equally in summarizing Study 3 findings. We calculated estimates for associations with ideal similarity and actual similarity using analyses for Studies 2 and 3, in that these studies assessed variance uniquely attributable to each variable. Figure 3 presents a meta-analytic summary of the observed direct and indirect associations among model variables; significant direct or indirect effects are designated by solid lines, and nonsignificant effects are designated by dashed lines.

\footnotetext{
${ }^{9}$ In several studies, we assessed traits that might moderate our findings. In Studies 1, 2, and 3, we measured self-esteem (Rosenberg, 1965) to rule out self-verification interpretations. If our findings are colored by selfverification motives, we should find that the benefits of ideal similarity are limited to people with high self-esteem (cf. Swann et al., 1994). In Studies 1,2 , and 3, we measured promotion and prevention orientation (Lockwood, Jordan, \& Kunda, 2002). Given that the Michelangelo process is linked to ideal self goals, we sought to determine whether the benefits of ideal similarity might be limited to people who possess strong promotion focus (concern with the ideal self) or weak prevention focus (concern with the ought self; cf. Higgins, 1987). And in Study 3, we measured clarity of self-concept to explore whether ideal similarity might yield benefits primarily to the extent that people have well-articulated self-concepts (e.g., they "know who they are and what they want"; cf. Campbell, 1990).

Replicating the previously reported analyses for Studies 1, 2, and 3, we regressed partner affirmation, target movement toward ideal, and couple wellbeing, in turn, simultaneously onto ideal similarity, each trait, and the interaction of ideal similarity with each trait (as well as, in Studies 2 and 3, actual similarity and the interaction of actual similarity with each trait). In these analyses, ideal similarity remained predictive of partner affirmation, target movement toward ideal, and dyadic adjustment ( $93 \%$ of the effects). In some instances, trait measures accounted for significant or marginal variance beyond ideal similarity. But it is important to note that there were very few interactions with traits (18\% of the interactions), and such effects were typically weak and inconsistent in direction. Thus, our findings do not appear to be moderated in meaningful ways by any of the traits that we examined.
} 
The meta-analysis revealed results that are consistent with our model, along with two additional direct effects. Models for ideal similarity revealed the predicted positive association with partner affirmation $(\beta=.23, p<.01$; see Figure 3$)$, as well as an indirect association with target movement toward ideal $(\beta=.26, p<.01)$; the association of ideal similarity with target movement is significantly mediated by partner affirmation $(z=3.04, p<.01)$; and the association of ideal similarity with couple well-being is significantly mediated by both target movement and partner affirmation $(z \mathrm{~s}=3.44$ and 2.31, respectively; both $p \mathrm{~s}<.01)$. Models for partner affirmation revealed the predicted positive association with target movement $(\beta=.44, p<.01)$, as well as an indirect association with couple well-being $(\beta=.32, p<.01)$; the association of partner affirmation with couple well-being is significantly mediated by target movement $(z=3.50, p<.01)$. The analyses also revealed the predicted positive association of target movement with couple well-being $(\beta=.35, p<.01)$. And finally, there was a positive association of actual similarity with partner affirmation $(\beta=.17, p<.02)$; the association of actual similarity with target movement is significantly mediated by partner affirmation $(z=2.02, p<.04)$, and the association of actual similarity with couple well-being is marginally mediated by target movement $(z=1.95, p<.06)$.

\section{General Discussion}

The present research sought to extend the literature regarding self processes by examining an interpersonal model of how people acquire skills, traits, and accomplishments. This work also sought to extend relationships science by identifying an interdependencebased explanation of similarity effects, examining the ways in which partner similarity to the ideal self may influence the Michelangelo process. Indeed, this is the first work to identify a couplelevel predictor of the Michelangelo process, to identify what it is about relationships that causes some partners to exhibit affirming behavior and some targets to enjoy greater movement toward their ideal selves. This research thereby bridges the person-focused and relationship-focused orientations in social psychology by examining the interpersonal bases of an important aspect of selfregulation, the means by which people move closer to (vs. further from) their ideal selves.

\section{Ideal Similarity and the Michelangelo Phenomenon}

Replicating earlier findings regarding the Michelangelo phenomenon (Drigotas et al., 1999; Kumashiro et al., 2007), the present work revealed that when close partners affirm one another by eliciting key elements of one another's ideals, each person enjoys personal growth, moving closer to his or her ideal self; when partners disaffirm one another, each person moves further from his or her ideals (see Figure 3). In addition, partner affirmation is associated with couple well-being and vitality in part because (a) affirmation promotes target movement toward the ideal self, which in turn promotes couple well-being, and in part because (b) affirmation also directly promotes couple well-being, above and beyond target movement toward ideal. The direct association of partner affirmation with couple well-being is a relatively reliable finding in work regarding the Michelangelo process. It appears that Elizabeth may experience Robert's affirmation as constructive for their relationship, even when it does not immediately promote movement toward her ideal self; conversely, she may experience his disaffirmation as destructive, even when she nevertheless manages to move closer to her ideals.

Consistent with predictions, we also found that ideal similarity is positively associated with partner affirmation, target movement toward the ideal self, and couple well-being. It is striking that the association of ideal similarity with couple well-being is indirect: Ideal similarity does not account for unique variance beyond partner affirmation and target movement toward ideal (see Figure 3). This finding has three important implications. First, it is particularly interesting in light of the fact that, traditionally, the association of ideal similarity with attraction has been explained in terms of aesthetic judgments (i.e., partners who resemble our ideal selves compare favorably to our ideal standards; cf. LaPrelle et al., 1990; Zentner, 2005). The present findings call into question the aesthetics-based explanation in that in our work, the benefits to couples of ideal similarity appear to be entirely interpersonal, wholly attributable to the Michelangelo process. Second, our work suggests that partners who resemble our ideal selves promote uniformly positive outcomes. These findings stand in contrast to previous work regarding the psychological threat induced by highperforming partners (cf. Herbst et al., 2003; Tesser, 1988). In terms of the constructs examined in the present work-including positivity on the part of the partner (affirmation), positivity on the part of the self (movement), and couple functioning - a partner who resembles one's ideal self would appear to be a rather unalloyed positive experience. A third important implication of this finding concerns its consequences for actual similarity: It is plausible that over the course of extended interaction, the fact that Robert is similar to Elizabeth's ideal self might yield increases in actual similarity; as Elizabeth moves closer to her ideals, she may increasingly come to resemble Robert (who actually possesses key elements of her ideal self). This intriguing possibility should be examined in future research.

Moreover, and congruent with our earlier speculation, ideal similarity promotes target movement toward the ideal self via two routes (see Figure 3). First, ideal similarity indirectly promotes target movement, in that partners who possess key elements of one another's ideal selves exhibit greater affirmation, which, in turn, promotes target movement toward the ideal self. Study 2 findings regarding mechanisms of affirmation suggest that ideal similarity promotes target movement because partners who possess key components of one another's ideals are more likely to believe in one another's potential, enact skillful affirmation, challenge one another, and exhibit responsiveness to one another's needs (see Table 3). Second, ideal similarity directly promotes target movement: Beyond variance attributable to partner affirmation, ideal similarity accounts for unique variance in target movement toward ideal. Future research should seek to identify the precise mechanisms by which ideal similarity (a very partner-oriented construct) promotes target growth beyond direct influence by partner affirmation (e.g., via target-centered, yet partner-oriented, mechanisms such as modeling or assimilation).

In a series of auxiliary analyses, we explored whether our findings might be attributable to alternative constructs with which one or more of our model variables might be associated, examining alternative explanations involving inclusion of other in the self, global social support, target idealization of the partner, commit- 
ment level, partner similarity to the partner's ideals, and socially desirable response tendencies. We also assessed whether several dispositions might moderate our findings, including self-esteem, promotion and prevention orientation, and clarity of self-concept. Using data from Studies 1, 2, and 4a, we found that these auxiliary analyses revealed that the predicted associations among model variables were reliably evident, even when we controlled for indices relevant to each of these alternative interpretations. We observed good support for model predictions not only in analyses employing self-report questionnaire measures but also in analyses that employed alternative measurement techniques (e.g., coderinteraction rating criteria, friend-report criteria). Thus, our findings appear to be robust and are not readily explained by alternative theoretical accounts.

\section{Actual Similarity and the Michelangelo Phenomenon}

The present work was concerned primarily with the effects of ideal similarity. At the same time, in light of the sizeable extant literature regarding the benefits of actual similarity, in Studies 2 and 3, we examined the effects of actual similarity in combination with ideal similarity. As predicted, associations with ideal similarity are not attributable to actual similarity: Ideal similarity reliably accounts for unique variance in model variables beyond actual similarity (see Figure 3). In addition, we found that actual similarity accounts for unique variance in partner affirmation beyond ideal similarity; the associations of actual similarity with target movement and couple well-being are wholly mediated by partner affirmation. Two aspects of these findings are striking. First, we speculated that actual similarity might be associated with couple well-being beyond benefits attributable to ideal similarity or to other model variables (e.g., by facilitating harmonious interaction). In light of innumerable studies documenting the association of actual similarity with attraction and couple well-being, it is striking that no such effects were evident in the present work. Instead, the benefits to couples of actual similarity were entirely attributable to the Michelangelo process, to the fact that actual similarity is associated with partner affirmation, which, in turn, promotes target movement toward ideal and couple well-being.

Second, in introducing our hypotheses, we speculated that actual similarity might promote the Michelangelo process, reasoning that Robert's similarity to Elizabeth's actual self might serve as a reality check, as a reminder of Elizabeth's actual potential for growth. As a consequence of possessing key elements of Elizabeth's actual self, Robert might better recognize the very real opportunities and constraints that she faces in attempting to achieve her ideals. If ideal similarity helps the sculptor sculpt toward the ideal figure, then actual similarity might help the sculptor recognize the realistic potential in the block of stone (e.g., where is the stone most beautiful, where are the flaws that must be circumvented?). As it turns out, this line of speculation proved to be well-founded. Actual similarity is positively associated with partner affirmation, which, in turn, fully mediates the association of actual similarity with target movement toward ideal. Study 2 findings regarding mechanisms of affirmation suggest that partners who resemble our actual selves may exhibit greater dedication to our ideals, may be more inclined to challenge us, and/or may offer better strategies for how we might pursue our ideals.

\section{Implications and Directions for Future Research}

One important implication of these findings is that, for better or worse, we are shaped by our loved ones. Of course, the ability to achieve our ideals is not entirely interpersonal: We develop some new skills, traits, and accomplishments through intrapersonal means. But the strength of the interpersonal effects observed in our work is striking. Thus, it is important to select an "admirable" partner, a partner who possesses key elements of one's ideals. It is interesting that our work revealed two forms of interpersonal regulation. The first type, the type emphasized in the Michelangelo model, might be termed partner-based interpersonal regulation: Partners can be friends or foes in our attempts to achieve our ideals; they can elicit the best or the worst in us, either affirming or disaffirming our ideal selves. But a second form of interpersonal regulation, target-based interpersonal regulation, was also evident: Above and beyond affirmation by Robert, Elizabeth enjoys movement toward her ideals when Robert resembles her ideal self, and she suffers movement away from her ideals when he does not. As noted earlier, in future work, it will be important to uncover the bases for such associations (e.g., modeling, assimilation).

A second important issue concerns implications for research regarding partner enhancement and verification. Relevant to our understanding of partner enhancement (cf. Murray \& Holmes, 1997), our findings suggest that the benefits of partner enhancement may be attributable not so much to receiving normatively positive evaluations from a partner but, rather, to receiving evaluations that are in line with one's ideal self. Indeed, in prior research, we demonstrated that it is more beneficial for Robert to elicit target attributes that are components of Elizabeth's ideal self (e.g., being a good poet) than to elicit attributes that are normatively desirable yet irrelevant to her ideal self (e.g., being beautiful; Drigotas et al., 1999). Relevant to our understanding of partner verification (cf. Swann, De La Ronde, \& Hixon, 1994), our findings demonstrate that, unlike verification effects, affirmation effects do not differ for targets with low versus high self-esteem (see Footnote 9): Robert's affirmation of Elizabeth is likely to yield commensurate benefits, whether Elizabeth has high self-esteem or low self-esteem. Moreover, in recent research, we demonstrated that affirmation and verification operate hand-in-hand, with both processes contributing to target movement toward the ideal self (Kumashiro et al., 2008). Indeed, we believe that verification may be beneficial not only because it confirms the target's pre-existing self-concept but also (or, perhaps, rather) because a partner who perceives the target's actual self may be more likely to provide realistic and informed affirmation. For example, a verifying partner may recognize real impediments to achieving one's ideals or may offer realistic strategies for pursuing one's ideals. This conceptualization of partners' contributions to one another's growth strivings may help clarify why partner verification is relatively more beneficial for specific traits, whereas enhancement is more beneficial for global traits (Neff \& Karney, 2002, 2005). For example, to act as a skilled sculptor, Robert may need to be aware of Elizabeth's specific strengths and limitations yet exhibit global, growth-relevant optimism or encouragement. In future work, the burgeoning subfield of relationships science should serve as a good guide for integrating seemingly divergent literatures regarding relationships, self processes, and goal pursuit. 
A third important issue that arises in connection with this work concerns the character of the Michelangelo process: Do partner affirmation and movement toward the ideal self come about as a consequence of controlled or automatic processes (cf. Chartrand \& Bargh, 2002; Fitzsimons \& Bargh, 2003; Shah, 2003)? For example, does partner affirmation necessarily rest on Robert's conscious knowledge of Elizabeth's ideal self, or can such knowledge be implicit? Also, does effective affirmation necessarily come about as a result of Robert's consciously articulated strategies about how to affirm Elizabeth, or can these processes also be automatic and/or implicit? For example, can Robert exhibit approval of Elizabeth's goal pursuits and encourage her pursuit of the ideal self in the absence of specific knowledge regarding the precise content of her ideal self and/or in the absence of any conscious intent to display affirming behaviors? Moreover, can Elizabeth enjoy movement toward her ideals in the absence of a well-articulated ideal self and/or in the absence of consciously articulated strategies for goal pursuit? It would be fruitful to explore these and related processrelevant issues in future research. Our work suggests that researchers who study the automatic versus controlled aspects of goal pursuits might benefit from an expanded field of study, examining not only the automatic versus controlled aspects of target-based intrapersonal processes but also the automatic versus controlled aspects of both target- and partner-based interpersonal processes.

A final implication of our findings concerns the broader literature regarding self processes. Traditionally, many "self" phenomena have been explained by reference to individual-level processes. Models of self-concept, self-esteem, and self-regulation have tended to utilize intrapersonal explanatory models, focusing on individual-level cognition, affect, and motivation (e.g., Bem, 1972; Carver \& Scheier, 1998; Steele, 1988). Over the past decade or so, we have observed a trend toward increasingly interpersonal models of self processes (e.g., Cosmides \& Tooby, 1992; Leary, Tambor, Terdal, \& Downs, 1995; Mischel \& Shoda, 1995; Tesser, 1988). We applaud this trend and believe that our work extends this new orientation. Given that the unique niche of our field concerns the social psychology of human behavior, we hope that the present work may serve as a basis for further explorations of inherently interpersonal properties of self-relevant phenomena.

\section{Strengths and Limitations}

Before closing, we should address several strengths and limitations of the present work. We have already noted several limitations. For example, in Studies 2 and 3, it was a challenge to analyze the unique variance attributable to ideal similarity and actual similarity, in that these variables were positively correlated. Study 3 employed a priming technique in which participants reacted to primed partners who were not "real." The data from Studies 1, 2, and 4a were from a single longitudinal study (albeit from different research occasions), thereby limiting the acrossstudy degrees of freedom available to interpret our findings. In Studies $4 \mathrm{a}$ and $4 \mathrm{~b}$, although we were gratified by the fact that ideal similarity reliably predicted change over time in model variables, we were unable to perform residualized lagged mediation tests because there was insufficient change in our criteria. No doubt, other limitations could also be identified.

But at the same time, several strengths of this research are also noteworthy. For example, we examined ideal similarity using multiple methods: We employed direct self-report measures in Studies 1 and $4 \mathrm{~b}$, we employed independent judgment tasks to construct multiple indirect indices of similarity in Studies 2 and 4a, and we actively manipulated similarity in Study 3. In addition, across the several studies, we used multiple means of assessing model criteria, including self-report questionnaires, friend-report questionnaires, data from an 8-day daily diary procedure, and both participant and coder ratings of target and partner behaviors during ideal-relevant conversations. In Studies 1 and 2, we demonstrated the validity of our measures by examining the correspondence between self-report measures and measures obtained using other techniques, observing good convergence of self-report variables with partner-report variables, friend-report variables, reports from daily diary variables, and both participant ratings and coder ratings of behaviors during ideal-relevant interactions. We observed good support for our predictions not only in within-person analyses but also in across-person analyses (i.e., in Studies 1 and 2, self-report questionnaire variables were associated with coder ratings of interactions and with friend-report variables). Moreover, in auxiliary analyses, we observed good support for our predictions in acrosspartner analyses (e.g., the partner's report of his/her affirmation of the target is associated with the target's report of his/her movement toward the ideal self). We also performed auxiliary analyses to help rule out several alternative explanations of our findings. In addition, we examined multiple participant populationsincluding stranger interactions, dating relationships, and newly committed relationships-and employed multiple research designs, including nonexperimental, experimental, and longitudinal designs. Given that there was minimal change over time in our Study $4 \mathrm{a}$ and $4 \mathrm{~b}$ criteria, it was particularly noteworthy that ideal similarity reliably predicts change in model criteria over a 6-month period. We believe that the converging operations approach is the strength of our work, and we believe that collectively, the studies reported herein serve as a good basis for confidence regarding our conclusions.

\section{Conclusions}

The primary goal of the present work was to extend our understanding of the Michelangelo phenomenon, an interpersonal model of the means by which people pursue - and sometimes achievetheir ideal selves. We argued that partner similarity plays an important role in this process, proposing that the Michelangelo process would be enhanced to the extent that close partners possess key elements of one another's ideal selves. Across multiple studies, we observed good support for our hypotheses, demonstrating that under conditions of ideal similarity, (a) partners exhibit greater affirmation, more effectively eliciting key elements of one another's ideal selves; (b) targets enjoy greater personal growth, moving ever closer to their ideal selves; and (c) couples thrive, exhibiting enhanced vitality and well-being. This work contributes to the literature regarding self processes by demonstrating the role that close partners play in shaping one another's goal pursuits; it contributes to the literature regarding the Michelangelo phenomenon by identifying a property of couples that reliably promotes this process; and it contributes to relationships science by identifying an interpersonal, growth-based explanation of the benefits of partner similarity. 


\section{References}

Aron, A., \& Aron, E. (2000). Self-expansion motivation and including other in the self. In W. Ickes \& S. Duck (Eds.), The social psychology of personal relationships (pp. 109-128). New York: Wiley.

Aron, A., Aron, E. N., \& Smollan, D. (1992). Inclusion of Other in the Self Scale and the structure of interpersonal closeness. Journal of Personality and Social Psychology, 63, 596-612.

Bandura, A. (1986). Social foundations of thought and action. Englewood Cliffs, NJ: Prentice-Hall.

Baron, R. M., \& Kenny, D. A. (1986). The moderator-mediator variable distinction in social psychological research: Conceptual, strategic, and statistical considerations. Journal of Personality and Social Psychology, 51, 1173-1182.

Beach, S. R. H., Tesser, A., Fincham, F., Jones, D. J., Johnson, D., \& Whitaker, D. J. (1998). Pleasure and pain in doing well, together: An investigation of performance-related affect in close relationships. Journal of Personality and Social Psychology, 74, 923-938.

Bem, D. J. (1972). Self-perception theory. In L. Berkowitz (Ed.), Advances in experimental social psychology (Vol. 6, pp. 1-62). New York: Academic Press.

Byrne, D. (1971). The attraction paradigm. New York: Academic Press.

Byrne, D., Ervin, C. E., \& Lamberth, J. (1970). Continuity between the experimental study of attraction and real-life computer dating. Journal of Personality and Social Psychology, 16, 157-165.

Campbell, J. D. (1990). Self-esteem and clarity of self-concept. Journal of Personality and Social Psychology, 59, 538-549.

Carver, C. S., \& Scheier, M. F. (1998). On the self-regulation of behavior. New York: Cambridge University Press.

Caspi, A., Herbener, E. S., \& Ozer, D. J. (1992). Shared experiences and the similarity of personalities: A longitudinal study of married couples. Journal of Personality and Social Psychology, 62, 281-291.

Chartrand, T. L., \& Bargh, J. A. (2002). Nonconscious motivations: Their activation, operation, and consequences. In A. Tesser, D. Stapel, \& J. Wood (Eds.), Self-motivation: Emerging psychological perspectives (Vol. 2, pp. 13-41). Washington, DC: American Psychological Association.

Condon, J. W., \& Crano, W. D. (1988). Inferred evaluation and the relation between attitude similarity and interpersonal attraction. Journal of Personality and Social Psychology, 54, 789-797.

Cooley, D. H. (1902). Human nature and the social order. New York: Scribner.

Cosmides, L., \& Tooby, J. (1992). Cognitive adaptations for social exchange. In J. H. Barkow, L. Cosmides, \& J. Tooby (Eds.), The adapted mind: Evolutionary psychology and the generation of culture (pp. 163228). New York: Oxford University Press.

Deci, E. L., \& Ryan, R. M. (2000). The "what" and "why" of goal pursuits: Human needs and the self-determination of behavior. Journal of Health and Social Behavior, 2, 237-256.

Drigotas, S. M. (2002). The Michelangelo phenomenon and personal well-being. Journal of Personality, 70, 59-77.

Drigotas, S. M., Rusbult, C. E., Wieselquist, J., \& Whitton, S. (1999). Close partner as sculptor of the ideal self: Behavioral affirmation and the Michelangelo phenomenon. Journal of Personality and Social Psychology, 77, 293-323.

Fitzsimons, G. M., \& Bargh, J. A. (2003). Thinking of you: Nonconscious pursuit of interpersonal goals associated with relationship partners. Journal of Personality and Social Psychology, 84, 148-164.

Fletcher, G. J., Simpson, J. A., \& Thomas, G. (2000). Ideals, perceptions, and evaluations of relationship development. Journal of Personality and Social Psychology, 79, 933-940.

Gable, S. L., Reis, H. T., Impett, E., \& Asher, E. R. (2004). What do you do when things go right? The intrapersonal and interpersonal benefits of sharing positive events. Journal of Personality and Social Psychology, $87,228-245$.
Gombrich, E. H. (1995). The story of art (16th ed.). London, England: Phaidon.

Gottman, J. M. (1979). Marital interaction: Experimental investigations. New York: Academic Press.

Herbst, K. C., Gaertner, L., \& Insko, C. A. (2003). My head says yes but my heart says no: Cognitive and affective attraction as a function of similarity to the ideal self. Journal of Personality and Social Psychology, 84, 1206-1219.

Higgins, E. T. (1987). Self-discrepancy: A theory relating self and affect. Psychological Review, 94, 319-340.

Higgins, E. T. (1997). Beyond pleasure and pain. American Psychologist, $52,1280-1300$

Ickes, W., Bissonnette, V., Garcia, S., \& Stinson, L. L. (1990). Implementing and using the dyadic interaction paradigm. In C. Hendrick \& M. S. Clark (Eds.), Review of personality and social psychology (Vol. 11, pp. 16-44). Newbury Park, CA: Sage.

James, W. (1890). The principles of psychology. New York: Holt.

Kelley, H. H. (1983). The situational origins of human tendencies: A further reason for the formal analysis of structures. Personality and Social Psychology Bulletin, 9, 8-30.

Kelley, H. H., Berscheid, E., Christensen, A., Harvey, J. H., Huston, T. L., Levinger, G., et al. (Eds.). (1983). Close relationships. New York: Freeman.

Kelley, H. H., \& Thibaut, J. W. (1978). Interpersonal relations: A theory of interdependence. New York: Wiley.

Kenny, D. A., Kashy, D. A., \& Bolger, N. (1998). Data analysis in social psychology. In D. T. Gilbert, S. T. Fiske, \& G. Lindzey (Eds.), Handbook of social psychology (4th ed., Vol. 1, pp. 233-265). Boston: McGraw-Hill.

Kenny, D. A., Kashy, D. A., \& Cook, W. L. (2006). Dyadic data analysis. New York: Guilford Press.

Klohnen, E. C., \& Luo, S. (2003). Interpersonal attraction and personality: What is attractive — self similarity, ideal similarity, complementarity, or attachment security? Journal of Personality and Social Psychology, 85, $709-722$.

Kumashiro, M., Rusbult, C. E., Coolsen, M. K., Wolf, S. T., van den Bosch, M., \& van der Lee, R. (2008). Partner affirmation, verification, and enhancement as determinants of attraction to potential dates: Experimental evidence of the unique effect of affirmation. Unpublished manuscript, University of Hamburg, Hamburg, Germany.

Kumashiro, M., Rusbult, C. E., Finkenauer, C., \& Stocker, S. L. (2007). To think or to do: The impact of assessment and locomotion orientation on the Michelangelo phenomenon. Personal Relationships, 24, 591-611.

LaPrelle, J., Hoyle, R. H., Insko, C. A., \& Bernthal, P. (1990). Interpersonal attraction and descriptions of the traits of others: Ideal similarity, self similarity, and liking. Journal of Research in Personality, 24, $216-240$.

Leary, M. R., Tambor, E. S., Terdal, S. K., \& Downs, D. L. (1995). Self-esteem as an interpersonal monitor: The sociometer hypothesis. Journal of Personality and Social Psychology, 68, 518-530.

Lockwood, P., Jordan, C. H., \& Kunda, Z. (2002). Motivation by positive or negative role models: Regulatory focus determines who will best inspire us. Journal of Personality and Social Psychology, 83, 854-864.

Lockwood, P., \& Kunda, Z. (1997). Superstars and me: Predicting the impact of role models on the self. Journal of Personality and Social Psychology, 73, 91-103.

Luo, S., \& Klohnen, E. C. (2005). Assortative mating and marital quality in newlyweds: A couple-centered approach. Journal of Personality and Social Psychology, 88, 304-326.

Markus, H., \& Nurius, P. (1986). Possible selves. American Psychologist, 41, 954-969.

Mischel, W., \& Shoda, Y. (1995). A cognitive-affective system theory of personality: Reconceptualizing situations, dispositions, and invariance in personality structure. Psychological Review, 102, 246-268. 
Murray, S. L., \& Holmes, J. G. (1997). A leap of faith? Positive illusions in romantic relationships. Personality and Social Psychology Bulletin, 23, 586-604.

Murray, S. L., Holmes, J. G., Bellavia, G., Griffin, D. W., \& Dolderman, D. (2002). Kindred spirits? The benefits of egocentrism in close relationships. Journal of Personality and Social Psychology, 82, 563-581.

Neff, L. A., \& Karney, B. R. (2002). Judgments of a relationship partner: Specific accuracy but global enhancement. Journal of Personality, 70, 1079-1112.

Neff, L. A., \& Karney, B. R. (2005). To know you is to love you: The implications of global adoration and specific accuracy for marital relationships. Journal of Personality and Social Psychology, 88, 480-497.

Newcomb, T. M. (1961). The acquaintance process. New York: Holt, Rinehart \& Winston.

Paulhus, D. L. (1984). Two-component models of socially desirable responding. Journal of Personality and Social Psychology, 46, 598-609.

Raudenbush, S. W., \& Bryk, A. S. (2002). Hierarchical linear models (2nd ed.). Thousand Oaks, CA: Sage.

Reis, H. T., \& Wheeler, L. (1991). Studying social interaction with the Rochester Interaction Record. In M. P. Zanna (Ed.), Advances in experimental social psychology (Vol. 24, pp. 269-318). New York: Academic Press.

Rosenbaum, M. L. (1986). The repulsion hypothesis: On the nondevelopment of relationships. Journal of Personality and Social Psychology, 51, $1156-1166$.

Rosenberg, M. (1965). Society and the adolescent self-image. Princeton, NJ: Princeton University Press.

Rusbult, C. E., \& Van Lange, P. A. M. (2003). Interdependence, interaction, and relationships. Annual Review of Psychology, 54, 351-375.

Sarason, B. R., Sarason, I. G., \& Gurung, R. A. R. (1997). Close personal relationships and health outcomes: A key to the role of social support. In S. Duck (Ed.), Handbook of personal relationships: Theory, research, and interventions (2nd ed., pp. 547-573). New York: Wiley.

Shah, J. (2003). Automatic for the people: How representations of signif- icant others implicitly affect goal pursuit. Journal of Personality and Social Psychology, 84, 661-681.

Simpson, J. A., Fletcher, G. J. O., \& Campbell, L. (2001). The structure and function of ideal standards in close relationships. In G. J. O. Fletcher \& M. S. Clark (Eds.), Blackwell handbook of social psychology: Interpersonal processes (pp. 86-106). Oxford, England: Blackwell.

Spanier, G. B. (1976). Measuring dyadic adjustment: New scales for assessing the quality of marriage and similar dyads. Journal of Marriage and the Family, 38, 15-28.

Stapel, D. A., \& van der Zee, K. I. (2006). The self salience model of other-to-self effects: Integrating principles of self-enhancement, complementarity, and imitation. Journal of Personality and Social Psychology, 90, 258-271.

Steele, C. M. (1988). The psychology of self-affirmation: Sustaining the integrity of the self. In L. Berkowitz (Ed.), Advances in experimental social psychology (Vol. 21, pp. 261-302). New York: Academic Press.

Swann, W. B., Jr., De La Ronde, C., \& Hixon, J. G. (1994). Authenticity and positivity strivings in marriage and courtship. Journal of Personality and Social Psychology, 66, 857-869.

Tesser, A. (1988). Toward a self-evaluation maintenance model of social behavior. In L. Berkowitz (Ed.), Advances in experimental social psychology (Vol. 21, pp. 181-227). New York: Academic Press.

Thibaut, J. W., \& Kelley, H. H. (1959). The social psychology of groups. New York: Wiley.

Wetzel, C. G., \& Insko, C. A. (1982). The similarity-attraction relationship: Is there an ideal one? Journal of Experimental Social Psychology, 18, 253-276.

Zentner, M. R. (2005). Ideal mate personality concepts and compatibility in close relationships: A longitudinal analysis. Journal of Personality and Social Psychology, 80, 242-256.

Received August 1, 2008

Revision received August 1, 2008

Accepted August 4, 2008 